\title{
A systematic framework for the design, simulation and optimization of personalized healthcare: making and healing blood
}

María Fuentes-Garí, ${ }^{\mathrm{a} b}$ Eirini Velliou, ${ }^{\mathrm{c}}$ Ruth Misener, ${ }^{\mathrm{d}}$ Eleni Pefani, ${ }^{\mathrm{a}}$ Maria Rende, ${ }^{\mathrm{b}}$ Nicki Panoskaltsis, ${ }^{\mathrm{e}}$ Athanasios Mantalaris, ${ }^{\mathrm{b}}$ Efstratios N.

Pistikopoulos ${ }^{\mathrm{a}^{*}}$

${ }^{a}$ Centre for Process Systems Engineering, Department of Chemical Engineering, Imperial College London, South Kensington Campus, London, SW7 2AZ, UK

${ }^{b}$ Biological Systems Engineering Laboratory, Department of Chemical Engineering, Imperial College London, South Kensington Campus, London, SW7 2AZ, UK

${ }^{c}$ Department of Chemical and Process Engineering, University of Surrey, Guildford, Surrey GU2 7XH

${ }^{d}$ Department of Computing, Imperial College London, South Kensington Campus, London, SW7 2AZ, UK

${ }^{e}$ Department of Haematology, Imperial College London, Northwick Park \& St. Mark's Campus, London, HA1 3UJ, UK

*Corresponding author: e.pistikopoulos@ic.ac.uk; Fax: +44-(0)20 7594 6606

\section{Highlights}

(1) The building blocks of a biomedical systems modeling framework are presented

(2) Interactions between building blocks are reviewed; two system types are described

(3) An example of a laboratory system type is described: artificial blood production

(4) An example of a patient system type is discussed: leukemia treatment optimization

(5) Other biomedical applications are briefly introduced as part of the framework 


\begin{abstract}
We review the key building blocks of a design framework for modeling and optimizing biomedical systems under development in the Biological Systems Engineering Laboratory and the Centre for Process Systems Engineering at Imperial College. The framework features the following components: (i) in vitro environment, where model parameters can be obtained and new setups can be tested; (ii) in silico environment, including a simulation module for representing relevant physical or biological processes, and an optimization module, for calculating of improved in vitro or in vivo outcomes; (iii) in vivo environment, from which organ and patient-specific parameters are collected and which can also implement personalized suggestions for improved outcomes. Two applications in the area of healthy and diseased blood are thoroughly discussed to exemplify the framework's characteristics. We discuss progress in the different areas and the way in which they are connected and finally propose a hybrid in vitro/in silico/in vivo platform.
\end{abstract}

Keywords: Biomedical design framework; Red blood cell production; Bioreactor design; Chemotherapy modeling and optimization for leukemia; Cell cycle; Environmental stress 


\section{Introduction}

One of the most prominent features of modeling biomedical systems is the existence of phenomena occurring at multiple scales. Between molecular, cellular, patient and population scales, appropriate translations are necessary for evaluating the effects small-scale processes have at large scale and vice-versa (Hall et al, 2011). Deriving patient data directly is not always possible, thus making ex vivo observations and studies imperative. For the latter to be accomplished it is essential to develop appropriate experimental setups that reproduce in vitro the biological characteristics and behavior of the in vivo system. In silico techniques may bridge the gap between the in vitro and in vivo scales, through simulating the patient response (Androulakis, 2014; Chen et al., 2012; Harrold and Parker, 2009; Ho et al, 2013). The study of normal and abnormal blood production faces these challenges and many others related to the complexity of the underlying biological system and the heterogeneity observed in hematological malignancies.

The current trends and developments in genomics, proteomics and metabolomics open the possibility for obtaining specific information related to the genetic characteristics, together with the proteomic and metabolomics profiles of an individual patient, which can then be used towards personalized medicine (Saha et al., 2014). In this context, personalized healthcare is expected to deliver a step change in quality and value of care, through more precise and personalized diagnostics as well as cost-effective and targeted therapies. Some of the challenges in the delivery of personalized medicine lie in (a) In vitro: the fidelity and validity of current experimental systems used to investigate human diseases; (b) In silico: the integration of patient-specific and disease-specific datasets and the development of validated predictive adaptive models; and (c) In vivo: the application of these models to identify simple targets and more efficient, yet less toxic therapies and drugs for a specific condition.

Here, we present the fundamental features of an integrated framework which aims to address (some of) these challenges - with main focus on healthy and diseased blood. An earlier version of this manuscript appeared as a conference manuscript (Velliou et al., 2014e); this full length manuscript clarifies and extends the previous work.

\section{Design framework.}

Figure 1 presents key building blocks of the integrated design framework under development at the Biological Systems Engineering Laboratory (BSEL) and the Centre for Process Systems Engineering (CPSE) at Imperial College. As a whole, the framework aims at closing the loop by collecting relevant data in vivo and/or in vitro in order to predict and/or improve real outcomes through in silico calculations.

From the scale point of view (represented as rows on Figure 1), biomedical systems' circuitry can be defined as the abstract representation of physiological 
processes into a network of compartments where exchange and/or reaction can take place at different levels. These physiological processes are subject to external cues that are tunable depending on medical/biological needs. Thus, the backbone of the design framework is composed of the following elements, under all three environments (in vitro, in vivo, in silico): (i) chemical stimulation: administering molecules capable of interacting with cellular material for inducing the desired transformation; (ii) molecular transport, either with biological modification (activation, degradation, elimination) or unmodified, to the target point of action; (iii) effect: molecular interaction with the target cells to transform their characteristics towards the desirable outcome; (iv) cell growth: stem cell proliferation, defining overall cell number which could then become susceptible to transformation; and (v) cell metabolism: cellular interaction with its environment to exchange the resources needed to sustain cell growth. Note that not all systems need accurate representations at all scales.

From the environment point of view (represented as columns on Figure 1), biomedical systems' processes are captured in vivo, in vitro and in silico. A particular system can incorporate two or more of the three environments: we will refer to in vitro / in silico systems as type 1, corresponding to laboratory setups, and to in vivo / in silico systems as type 2, tackling clinical treatment at the patient level.

Type 1 systems feature an existing in vitro component which delivers a valuable product (cells, proteins, etc...) whose quality / quantity / cost is not satisfactory enough. Experimental data can be readily obtained (in accordance to GSA findings) and used to determine model parameters. The in silico component features mathematical representations of the relevant biological and physical processes occurring in vitro, simulating the experimental setup based on the aforementioned parameters. In silico optimization then computes an optimal scenario in which values of the operating variables are found that minimize cost / maximize production / achieve a certain quality (all according to in vivo specifications), while satisfying the required constraints.

Type 2 systems are composed of an in vivo component, corresponding to a particular patient undergoing medical treatment. Patient characteristics (in vivo specifications) and details of the treatment clinically administered are used to derive patient-specific parameters. Body processes affecting or affected by the medical treatment in vivo are rendered in silico through appropriate mathematical equations simulating patient response. Sensitivity analysis on the model points out which model parameters are most significant. If those parameters are not available from in vivo measurements, experiments have to be designed in order to specifically obtain the required parameters in vitro. Finally, in silico optimization calculates the optimal scenario on a case-by-case basis, by delivering values of the operating variables for maximizing treatment efficiency / minimizing side-effects / minimizing treatment cost, in accordance with medical constraints. 
This manuscript applies our systematic framework to two healthcare domains that exemplify type 1 and type 2 systems respectively (Sections 3 and 4): artificial blood production and personalized leukemia treatments. A brief overview of how the framework is applied to the treatment of diabetes and the control of anesthesia is given in Section 5.

\section{Artificial blood production: an example of a type 1 system}

Over fifteen million whole blood units are collected in the USA yearly (National Blood Collection and Utilization Survey, 2011); 1.9 million blood units were collected in the UK between 2012-2013 (NHS Blood and Transplant). But despite the success of coordinated blood collection and utilization: $3.3 \%$ of hospitals delay surgery because of blood shortages and $10.3 \%$ of hospitals experience at least one day yearly when blood needs cannot be met (Timmins and Nielsen, 2009; Whitaker and Henry, 2011). Beyond shortages of commonly-stocked blood types, patients undergoing regular transfusions may require expensive rare blood donation to mitigate the risk of an immune response to foreign antigens (Tahhan et al., 1994; Meny et al., 2013). Ex vivo blood production is an attractive solution for filling shortage gaps and scaling-up rare blood donations. Current blood expansion protocols however require $\$ 8330$ per unit of blood when an average hospital in the USA pays only $\$ 225.42$ for a typical unit of blood and $\$ 1150$ to $\$ 3025$ for a unit of rare blood (Timmins and Nielsen, 2009; Whitaker and Henry, 2011; Meny et al., 2013). Clearly, a more cost-effective solution needs to be implemented in order to shift towards artificial blood supply (Rodrigues et al., 2011).

We propose a platform for on-demand artificial blood production, wherein umbilical cord HSCs are cultured in a biomimetic, cost-effective, 3D bioreactor, expanded and differentiated into red blood cells by careful signaling to externally control the same process of blood production that is diseased in leukemia (green panels, Figure 1).

\subsection{In vitro: A novel 3D bioreactor for ex-vivo culture of healthy and diseased blood}

Blood cell production takes place in the bone marrow (BM), a highly porous three dimensional organ of great complexity, where hematopoietic stem cells (HSCs) reside. HSCs in the BM receive appropriate signals to proliferate and specialize towards functional cellular units of the immune and oxygen-carrying systems (Quesenberry et al., 2001). These signals consist of both chemical (nutrients, oxygen and growth factors, which are signaling proteins that provide extracellular stimuli to the cells) and mechanical (adhesion, cell-cell contact) stimuli unique to the 3D microenvironment (Panoskaltsis et al., 2005). However, most current research is still performed in 2D culture systems, wherein the mechanical stimuli received by the cells are nonnative and thus the cellular proliferation is reduced. This limitation is typically overcome by increasing chemical stimulation from the expensive, specialized growth factor 
proteins (Timmins and Nielsen, 2009). Taking into consideration the BM microenvironment architecture, we describe, in the sequel, development of two $3 \mathrm{D}$ in vitro platforms which serve as an in vitro bone marrow mimicry allowing the expansion of normal and diseased blood.

A 3D micro-bioreactor was developed by Mortera et al. (2010, 2011), consisting of highly porous Polyurethane (PU, pore size approximately $100 \mu \mathrm{m}$ ), of dimensions $5 \times 5 \times 5 \mathrm{~mm}$, as shown in Figure 2, which allows perfusion of nutrients and oxygen within the matrix. This micro-bioreactor successfully supported expansion and differentiation of Umbilical Cord Blood cells (blood cells with high proliferation/differentiation potential) without any exogenous cytokines for a time frame of 4 weeks, in contrast to traditional 2D culture systems that allowed Umbilical Cord Blood cells expansion only for a few days in absence of exogenous growth factors. However, in order to produce blood at quantities sufficient for transfusion purposes, it is essential to scale up the ex vivo blood expansion (Rousseau et al., 2014).

Moving on that direction, we developed a 3D perfusion bioreactor (HFBR) capable of producing artificial blood (see Figure 3a; patented by Panoskaltsis et al., 2012). The HFBR enables red blood cell expansion at higher and continuous rate, by incorporating circulation of oxygenated nutritious medium, growth (stem cell factor - SCF) and differentiation (erythropoietin - EPO) factors. From an architectural point of view, the bioreactor is composed of a 3D polyurethane scaffold traversed by two different circuits as shown in Figure 3a, (i) a highuptake nutrient delivery circuit delivers nutrients and oxygen and removes waste through a plastic hollow fiber with very narrow pore size, (ii) a lowuptake protein delivery circuit circulates EPO and SCF through a ceramic hollow fiber with larger pore size, allowing the exit of mature red blood cells (RBC) only. It recapitulates the architectural and functional properties of blood formation and thereby reduces the need for expensive growth factors by more than an order of magnitude. The RBCs produced comply with the in vivo specifications in terms of oxygen-carrying capacity, surface markers, and shape (Macedo, 2011).

In comparison to other solutions for HSCs expansion, our HFBR achieves:

(1) 10x lower cost (for the same cell production) with $28 \mathrm{x}$ lower bioreactor volume (for 1 unit of RBCs) (vs. perfusion bioreactor, Engelhardt et al, 2011)

(2) $18 x$ higher cell production starting from the same cell density (vs. hollow fiber bioreactor, Chaudhuri and Al-Rubeai, 2005)

(3) $5 x$ lower cost (for the same cell production) with 4000x smaller volumes (vs. 2D, Neildez-Nguyen et al., 2002) 
Experiments in the bioreactor are typically cost- and labor- intensive. Applying in silico optimization strategies for the design and operation of the bioreactor can be highly beneficial, as reviewed in the next section.

\subsection{In silico: Bioreactor design optimization}

Modeling in the bioreactor presented in Section 3.1 occurs across different scales: cellular growth, metabolism, fluid dynamics and chemical diffusion. Specifically, chemical stimulation is achieved by supplying SCF and EPO. Transport in the HFBR happens in two directions: perfusion of nutrients, oxygen and proteins in the bioreactor is modeled as axial flow within the fibers (3e), while diffusion in the scaffold occurs radially (3d). Mass exchange with cells within the scaffold results in the specific effects of the specialized proteins: growth (SCF) and differentiation (EPO). In the model, glucose corresponds to cellular nutrients for cell growth; lactate represents waste; oxygen stands in for cellular metabolism. The mathematical model for cellular growth, proliferation, and differentiation is derived from Ma et al. (2012) and Colijn et al. (2005). The model is implemented in GAMS 24.1 and solved using the MINLP solver ANTIGONE 1.1 (Misener and Floudas, 2013; 2014).

Optimization aims at minimizing the cost of producing one unit of RBC while providing enough nutrients/growth factors to satisfy the quality requirements. The objective function is the sum of the costs involved in operating the bioreactor. Superstructure optimization impacts not only how the bioreactor is operated but also the way it is designed. Design choices consist of: (i) external diameter and length (aspect ratio) of the cylindrical bioreactor; (ii) number of hollow fibers for delivering reactants and extracting products and by-products. Operating choices include: (i) flow rate of nutritious medium through the bioreactor; (ii) medium inlet composition in terms of glucose and growth factors, (iii) ambient oxygen concentration. The optimization is constrained by a minimum red blood cell yield and by a sufficient amount of stem cells remaining in the HFBR until the end of culture.

Solving the nominal bioreactor model is valuable because it indicates general guidelines for how to construct the bioreactor; in Misener et al. (2014b), we showed that the costs are competitive with rare blood transfusions (i.e., transfusions for patients with special needs). However both the parameters and the underlying model itself are uncertain; therefore it is critical to incorporate uncertainty and what-if scenarios into the analysis. Sensitivity analysis defines which parameters are significant; we have proposed robust optimization for handling the uncertainty of those parameters and used multiple runs of the same optimization model to explore alternative scenarios (Misener et al., 2014a; 2014b). Recall that robust optimization inoculates against uncertainty by considering the worst-case realization of the parameters when optimizing the system (Ben-Tal and Nemirovski, 2000). Many of the bioreactor design choices 
remain constant despite parameter or model changes. For example, the optimization model consistently favors bioreactors that are:

(1) long, this results from the fixed costs per bioreactor;

(2) thin, this reduces the dead zones from mass transfer limitations;

(3) packed with as many hollow fibers as possible, this facilitates mass transfer;

(4) operated at a high flow rate, the best mass transfer occurs with flow rates as high as possible which will not damage the hollow fiber membranes.

But other of the bioreactor design choices are highly sensitive to variability. For example, there are two types of hollow fibers in the bioreactor; the polymeric hollow fibers deliver nutrients and clear waste while the ceramic hollow fibers deliver specialized proteins (i.e., growth factors) and harvest cells. Because the purpose of the bioreactor is harvesting red blood cells, the optimization algorithm will always try to maximize the number of ceramic hollow fibers subject to including enough polymeric hollow fibers for nutrient delivery. But uncertainties in mass transfer and cell kinetics make determining the minimum number of polymeric hollow fibers difficult; the tradeoff is between making each individual bioreactor more likely to function properly by including more polymeric hollow fibers or making the bioreactors which function properly incorporate more cell-harvesting ceramic hollow fibers. Robust optimization helps quantify these tradeoffs (Appendix 1).

\section{Optimal personalized treatments for leukemia: an example of a type 2 system}

BM failure is characterized by the inability of HSCs to produce healthy blood cells at an acceptable rate and quality, leading to a variety of health issues and diseases, including leukemia. Leukemia is a cancer of the hematopoietic system characterized by the incapability of blood progenitors (HSCs) to mature normally; this induces immature white blood cells accumulation in the bone marrow (Williams, 1983). Acute Myeloid Leukemia (AML) is the second most common type of leukemia (34\% of all leukemias, 2011, Cancer Research UK); it affects only cells from the myeloid blood lineage. According to Cancer Research UK, approximately 3.4 new cases of AML occur annually per 100,000 people in the UK alone (2011).

The most frequent treatment for AML is chemotherapy which aims at eliminating the cancerous BM population by attacking highly proliferative cells (immature blasts) (Cancer Research UK, American Cancer Society). Chemotherapy represents a reactive approach to the disease initiating after the disease symptoms appear. Current chemotherapy treatment protocols are designed based on: (i) pre-clinical animal experiments, (ii) empirical clinical trials, and (iii) 
the acquired experience of subspecialist physicians. However, leukemia exhibits a very high heterogeneity both between patients and also within a specific patient (Preisler et al., 1995); this heterogeneity leads to unpredictable treatment outcomes. Clinical treatment protocols for AML could, therefore, benefit from a more rational and personalized treatment scheduling strategy.

Increasingly, implementing more advanced pharmacokinetic/pharmacodynamic models becomes critical for applying personalized treatment. Additionally, linking a small subset of measurable variables to unique individual characteristics is necessary. Ultimately, applying such a tool could inform not only optimal timing and type of personalized treatment for improved outcomes, but also provide a platform for pre-clinical assessment of novel targeted therapies for leukemia and other cancers (Heitzig et al., 2014). Here, we review our efforts in simulating and optimizing chemotherapy treatment, from the time the drug is given to the patient, followed by the circulation in the body until it reaches its target (the bone marrow where leukemia resides) and finally the calculation of its effect according to cellular susceptibility (defined by the proliferative state) (Pefani et al., 2013; 2014). Detailed building blocks are illustrated in blue, Figure 1.

\subsection{In vivo: Clinical data collection from patients undergoing treatment for AML}

Standard treatment for AML is chemotherapy, with normally two different drugs: cytarabine (Ara-C) and daunorubicin (DNR). Ara-C is given twice a day for 10 days in a row, while DNR is given as a pulse on days 1, 3 and 5. These chemotherapeutic drugs act at a particular point of cell duplication. Clinical dosage (per body-surface area, BSA) and infusion route depend on overall patient fitness and age. Dosage is calculated according to the patient's weight and height measurements (BSA). In vivo specifications include all the details of the treatment (dose, schedule, infusion route etc...), patient characteristics (age, weight, height) and any tests performed (percentage of AML cells prior to chemotherapy, any follow-up measurements).

\subsection{In silico: Chemotherapy treatment optimization for $A M L$}

Figure 4 represents an overview of the optimization model structure. For simulation purposes, the particular drug and schedule (chemical stimulation) chosen by the doctor is used as a known input for the model (Pefani et al., 2013).

Pharmacokinetics (PK) considers the transport and transformation the drug undergoes once it reaches the blood streams, and in turn the relevant organs which absorb it at different rates. Mass balances are performed in each of these organs, giving the drug concentration profiles. Parameters for this compartment include patient characteristics and treatment schedule, which can be derived from clinical data (always reported). 
Chemotherapy interacts with cells that are proliferating; more specifically, only cells that are in one of the cell cycle phases (i.e., duplicating cells) are eliminated. Accordingly, detailed cell cycle equations, modeling the point of drug action are needed. Drug pharmacodynamics (PD) can be applied in this way to the susceptible cell cycle compartments of the proliferating populations. The drug concentration profiles calculated in the PK model are the only input required for the PD model, in which the drug effect on cell growth is computed according to cell cycle kinetics of each population. Since healthy cells also proliferate in order to renew the cellular material, they will equally be affected; it is very important to keep a balance between the number of cancer cells killed and the loss of healthy cells.

Cell growth is modeled differently for normal and abnormal cells. Because most of the cancer cells are proliferating, the cell cycle model in this case incorporates 3 compartments in which the cells are non-resting (G0/G1, where cells grow and stock up on nutrients, $\mathrm{S}$, where cells duplicate their DNA, and G2/M where cells divide; Morgan, 2007). Each of them is described by the mass balance between compartments (including cell death by drug action if applicable). The transition rates are dependent on cell cycle times and natural apoptosis rates in each of the phases (Basse et al., 2003); cell cycle kinetics are modeled through a set of Ordinary Differential Equations (ODEs) (one per compartment, see Appendix 2) (Pefani et al., 2014). The normal cell population model considers a proliferative population and a resting population that can move into a proliferative state, which are modeled as delay differential equations. A more refined multi-stage population balance model (MS-PBM) of the cell cycle was introduced by Fuentes-Garí et al. (2014b), based on the work of García Münzer et al. (2013, 2014). Duplication times of leukemic cells can be inferred from the number of cancer cells before and after treatment (if clinically performed). However, more specific information on the distribution within each phase is unavailable clinically and has to be determined experimentally (if required - see Section 4.3).

Cellular metabolism is an important phenomenon in the area of cancer, as it influences both the tumor growth rate and its susceptibility to drugs. To mathematically model cellular metabolism, a mechanistic description of those phenomena is essential. Advanced genetic and metabolic laboratory analysis will enable the accurate correlation of environmental stress with the cell cycle via the detection, selection and quantification of intracellular biomarkers that have a key role on the cell stress response. Mathematical models linked to cell growth have been also developed by our group (Kiparissides et al., 2011) and will be critical in tackling personalized treatment for patients with hypo- or hyper- glycemia, diabetes, etc. No information on cellular metabolism is provided on clinical reports; any data required for parameter estimation must be obtained from experiments on the leukemic cells. 
4.3. From in silico to in vitro: sensitivity analysis and design of experiments Insufficient in vivo data for the in silico cellular growth compartment requires the application of global sensitivity analysis to point out which are the parameters needed. GSA was performed on ODE and MS-PBM cell cycle models (Pefani 2014; Fuentes-Garí et al., 2014b) and identified the duration of each of the cell cycle phases as the most significant parameter for the cell cycle distribution (see Appendix 3 for a definition, Kiparissides et al. (2009) for its application to biological systems). Experiments were designed to accurately determine the sensitive parameters, based on the segregation of cells into two approximately synchronous populations (for the extraction of cell cycle times, Section 4.4.).

\subsection{In vitro: Laboratory data collection from AML patient cells}

Sensitivity analysis carried out in Fuentes-Garí et al. (2014b) identified cell cycle kinetics as one the key factors affecting treatment outcomes (Section 5.2). Therefore experimental efforts were directed towards (i) the determination of the duration of each of the cell cycle phases, (ii) the determination of the impact of environmental factors, such as oxygen and glucose concentration on the growth and cell cycle evolution, as fluctuations in the different body compartments and between AML patients (individual cases of hypoglycemia, hyperglycemia) may lead to a different leukemic cell metabolism (see as examples Herst et al., 2011; Lodi et al., 2011; Zhou et al., 2010).

The 3D culture system of Section 3.1 provides an ideal laboratory platform to cukture hematopoietic cells donated by AML patients (Rende et al., 2013), exposing to measurement parameters crucial for cancer evolution including: cellular growth, cellular metabolism and drug effect. However, proof of concept studies linking in vitro to in silico are required as a first step to validate the experimental design and possibility to measure the parameters required. These studies are therefore carried out with leukemic cell lines (easy to handle, lab adapted cells), under 2D or 3D conditions.

A chase experiment (Figure 5b.), which tracks labeled cells as they progress through the cell cycle, was designed to obtain the parameters necessary to run the leukemia cell growth model. Input information consisted on initial conditions (cell number) and experimental schedule (duration, sampling frequency). Parameter values for the cell cycle times of three different leukemia cell lines (K-562, MEC-1 and MOLT-4) were determined experimentally by following the timings of entry and exit events of a subpopulation of cells to and from each of the phases under 2D conditions at a first step (Fuentes-Garí et al., 2014a; 2014b). The parameters were then used to run the model and validate it against independent cell cycle data; good agreement was observed in all three cases. 
To determine the impact of cellular metabolism on cellular growth, we compared in vitro the proliferation, cell cycle and metabolic evolution of an AML model system (K-562 cell line) in our 3D micro-bioreactor (Section 3.1) and in a conventional 2D culture for 2 weeks (Velliou et al., 2013; 2014a; 2014b; 2014c). Different oxygen (5\%: hypoxia; 20\%: normoxia) and glucose conditions $(4.3 \mathrm{~g} / \mathrm{L}$ : standard lab; $1.3 \mathrm{~g} / \mathrm{L}$ : highest in vivo; $0.6 \mathrm{~g} / \mathrm{L}$ lowest in vivo) were used (Figure 5c.). In both the $2 \mathrm{D}$ and the 3D system, glucose is identified as the limiting factor that highly affects the kinetic evolution of K-562 only under hypoxic conditions (Figure 6). As can be seen in Figure 7, in general, oxidative stress leads to a higher accumulation of cells in the resting phase (G0) of the cell cycle, in comparison to $20 \% \mathrm{O}_{2}$, for both hypo and hyperglycemic levels of glucose.

In order to assess the impact of cellular metabolism on drug effects, K-562 was pre-cultured for one week under the aforementioned conditions and exposed to $10 \mathrm{mg} / \mathrm{L} \mathrm{Ara-C}$ drug for $48 \mathrm{~h}$ (Figure $5 \mathrm{~d}$., Figure 8); cells cultivated in hypoxia had a higher survival. This illustrates the connections between cell metabolism, cell growth and chemotherapy effects, and justifies the design of more advanced experiments that could provide enough data for parameter estimation in future models.

\section{Beyond healthy and diseased blood: treatment of diabetes and control of anesthesia as additional examples of type 2 systems}

\subsection{Optimizing the treatment of diabetes: automated insulin dosing}

Type 1 diabetes mellitus is a disease affecting the pancreatic production of insulin, which regulates glucose consumption in the body. Frequent administration of exogenous insulin is required in order to maintain glucose levels in the blood within safe concentrations. Recently, efforts have been made to develop a more convenient and reliable alternative: the Artificial Pancreas (Zavitsanou et al., 2011; Dassau et al., 2013). In the Zavitsanou et al. (2011) in silico model of the glucoregulatory system, two chemical stimuli are delivered: via meals (glucose), and via insulin administration. Insulin enters directly the blood streams, making a transport (PK) compartment unnecessary in this case. After a meal, the digestion process delivers glucose to the blood streams. Transport to the organs is described by the glucose metabolism PK compartment. The PD compartment assesses the effect that insulin has on glucose levels in blood. The optimization problem aims at obtaining the optimal insulin profile that minimizes the time glucose is outside of the normal range.

\subsection{Anesthesia dosage as a control problem}

Volatile anesthesia is administered to achieve hypnosis in a patient prior to surgery. Clinically, anesthesia is dosed by medical specialists and requires a high degree of expertise. Anesthesia was previously addressed as a control problem in Krieger et al. (2014). The goal was to personalize drug dosage and 
scheduling according to patient characteristics (weight, height, age, gender) and at a second step adjust it online according to measured response in vivo. In this problem, the chemical stimulus is the anesthetic agent which is delivered to the lungs through inhalation. It is transferred through the pulmonary capillaries to the blood streams, which transport the agent to other body compartments and tissues (muscles, skin, adipose tissue). For the in silico compartment, the PK model is composed by the mass balances between each of those compartments. Parameters required include patient characteristics and the dose administered. The PD model quantifies the hypnotic effect according to the PK dose, measured through the bispectral index. Sensitivity analysis found PD model parameters to be the most significant and vary widely across patients. The optimization and control problem on-line remains to be addressed, but on-line updates based on patient measurements could compensate for inaccurate PK parameters and deliver estimated PD parameters, increasing accuracy and patient-specificity of the protocols suggested.

\section{Conclusions and future perspectives}

An integrated framework was reviewed that addresses the design, modeling and optimization of biomedical systems.

The first application presented is the optimization of healthy blood production artificially, comprising in vitro and in silico components. A self-contained bioreactor with promising RBC expansion capabilities in vitro was constructed. In preparation for large scale artificial blood production, optimization of the bioreactor superstructure in silico defined the optimal physical bioreactor layout and operation in order to minimize the cost of producing one unit of blood.

The second application presented is the optimization of chemotherapy treatment strategies in leukemia, featuring in vivo, in vitro and in silico components. A predictive tool for the optimization of chemotherapy delivery was developed which a priori suggests patient-specific treatments with outcomes better than those resulting from current clinical protocols. Since in vivo specifications for each patient do not provide all the information required, the most significant parameters needed in silico for cellular growth are obtained in vitro. Moreover, cellular metabolism should be taken into consideration when designing a chemotherapy protocol as it significantly alters the cellular growth and drug action.

An overview of two additional applications was given, in the areas of insulin dosing for diabetes and control of anesthesia. In the former, the framework was applied to the optimal dosage of insulin taking into account the very unpredictable patterns of food intake of the patient. The latter exemplifies a system where the control strategy can be adjusted online according to patient measurements. 
Future work in the area of normal and abnormal blood expansion will focus on elucidating key mechanisms/factors of genetic or proteomic/metabolomics. Quantitative information on these key mechanisms will serve as an appropriate input for the construction of more detailed predictive models for the in silico description of healthy and diseased blood evolution. Quantification of appropriate intra-cellular biomarkers that are related to the blood in vitro kinetics can enable the combination of macroscopic kinetics with microscopic information both at normal and stressful environmental conditions (Velliou et al., 2014d). The latter will eventually lead to the construction of more detailed models of grey or white box nature, that will allow a much more accurate prediction of the cellular evolution of healthy and diseased blood.

\section{Acknowledgements}

This work was supported by ERC-BioBlood (no. 340719), ERC-Mobile Project (no. 226462), by the EU 7th Framework Programme [MULTIMOD Project FP7/2007-2013, no 238013] and by the Richard Thomas Leukaemia Research Fund. R.M. is further thankful for a Royal Academy of Engineering Research Fellowship. 


\section{References}

I.P. Androulakis, 2014, A chemical engineer's perspective on health and disease, Computers \& Chemical Engineering, 71, 665-671.

B. Basse, B.C. Baguley, E.S. Marshall, W.R. Joseph, B.V. Brunt, G. Wake, 2003, A mathematical model for analysis of the cell cycle in cell lines derived from human tumours, Mathematical Biology, 47, 295-312.

A. Ben-Tal and A. Nemirovski, 2000, Robust solutions of linear programming problems contaminated with uncertain data. Math. Prog., 88, 3, 411-424.

J. Chaudhudi, M. Al-Rubeai, 2005, Bioreactors for tissue engineering: principles, design and operation, Springer, Netherlands.

T. Chen, N.F. Kirkby, R. Jena, 2012, Optimal dosing of cancer chemotherapy using model predictive contro and moving horizon state/parameter estimation, Computer Methods and Programs in Biomedicine, 108, 3, 973-983.

C. Colijn, M.C. Mackey, 2005, A mathematical model of hematopoiesis-I. Periodic chronic myelogenous leukemia, Journal of Theoretical Biology, 237, 2, 117-132.

E. Dassau, H. Zisser, R.A. Harvey, M.W. Percival, B. Grosman, W. Bevier, E. Atlas, S. Miller, R. Nimri, L. Jovanovic, F.J. Doyle III, 2013, Clinical evaluation of a personalized artificial pancreas, Diabetes Care, 36, 4, 801-9.

M. Engelhardt, J. Douville, D. Behringer, A. Jahne, A. Smith, A. Henschler, W. Lange, 2001, Hematopoietic recovery of ex vivo perfusion culture expanded bone marrow and unexpanded peripheral blood progenitors after myeloblastive chemotherapy, Bone Marrow Transplant, 27, 3, 249-259.

M. Fuentes-Garí, R. Misener, D. García-Münzer, E. Velliou, M. Georgiadis, M. Kostoglou, N. Panoskaltsis, E. N. Pistikopoulos, A. Mantalaris, 2014a, Development and experimental validation of a cyclin-based population balance model of the cell cycle in leukemia cell lines, Journal of Tissue Engineering and Regenerative Medicine, 8, 489.

M. Fuentes-Garí, R. Misener, D.G. García-Münzer, E. Velliou, M. Kostoglou, M. Georgiadis, N. Panoskaltsis, E.N. Pistikopoulos, A. Mantalaris, 2014b, A validated mathematical model of sub-population kinetics for the deconvolution of leukemia heterogeneity (submitted).

D.G. García Münzer, M. Kostoglou, M. Georgiadis, E.N. Pistikopoulos, A. Mantalaris, 2013, Developing a cyclin blueprint as a tool for mapping the cell cycle in GS-NS0, Biochemical Engineering Journal, 81, 97-107.

D.G. García Münzer, M. Kostoglou, M.C. Georgiadis, E.N. Pistikopoulos, A. Mantalaris, 2014, A Cyclin Distributed Cell Cycle Model in GS-NS0, in J. J. Kleměs, P. S. Varbanov, P. Y. Liew (Ed.), 24th European Symposium on Computer Aided Process Engineering. Vol. 33 of Computer-Aided Chemical Engineering. Budapest, Hungary, 19-24.

C. Hall, E. Lueshen, A. Mošat', A.A. Linninger, 2011, Interspecies scaling in pharmacokinetics: A novel whole-body physiologically based modeling framework to discover drug biodristribution mechanisms in vivo, Journal of Pharmaceutical Sciences, 101, 3, 1221-1241.

J. M. Harrold, R.S. Parker, 2009, Clinically relevant cancer chemotherapy dose scheduling via mixed-integer optimization, Computers \& Chemical Engineering, 33, 12, 2042-2054.

M. Heitzig, A.A. Linninger, G. Sin, R. Gani, 2014, A computer-aided framework for development, identification and management of physiologically-based pharmacokinetics models, Computers \& Chemical Engineering, 71, 677-698. 
P.M. Herst, R.A. Howman, P.J. Neeson, M.V. Berridge, D.S. Ritchie, 2011, The level of glycolytic metabolism in acute myeloid leukaemia blasts at diagnosis is prognostic for clinical outcome, Journal of Leukocyte Biology, 89, 51-55.

T. Ho, G. Clermont, R.S. Parker, 2013, A model of neutrophil dynamics in response to inflammatory and cancer chemotherapy challenges, Computers \& Chemical Engineering, 51, 187-196.

A. Kiparissides, S. Kucherenko, A. Mantalaris, E.N. Pistikopoulos, 2009, Global Sensitivity Analysis Challenges in Biological Systems Modeling, Industrial \& Engineering Chemistry Research, 48, 15, 7168-7180.

A. Kiparissides, M. Koutinas, C. Kontoravdi, A. Mantalaris, E.N. Pistikopoulos, 2011, 'Closing the loop' in biological systems modeling — From the in silico to the in vitro, Automatica, 47, 6, 1147-1155.

A. Krieger, N. Panoskaltsis, A. Mantalaris, MC Georgiadis, E.N. Pistikopoulos, 2014, Modeling and Analysis of Individualized Pharmacokinetics and Pharmacodynamics for Volatile Anesthesia. IEEE Transactions in Bio-Medical Engineering, 61, 1, 25-34.

A. Lodi, S. Tiziani, F.L. Khanim, M.T. Drayson, U.L. Gunther, C.M.Bruce, M.R. Viant, 2011, Hypoxia triggers major metabolic changes in AML cells without altering indomethacin-induced TCA cycle deregulation, ACS Chemical Biology, 6, 169-175.

C. Ma, N. Panoskaltsis, R. Kumar, X. Xu, A Mantalaris, 2012, Simulation of ex vivo bone marrow culture: Application to chronic myeloid leukaemia growth model, Biochemical Engineering Journal, 61, 66-77.

H. Macedo, 2011, A novel 3D dual hollow fibre bioreactor for the production of human red blood cells, Ph.D thesis, Imperial College London, UK.

G. M. Meny, C. Flickinger, C. Marcucci, 2013, The American rare donor program. J Critical Care, 28, 1.

R. Misener, C.A. Floudas, 2013, GloMIQO: Global Mixed-Integer Quadratic Optimizer, Journal of Global Optimization, 57, 3-50.

R. Misener, C.A. Floudas, 2014, A framework for globally optimizing mixed-integer signomial programs. J Optim Theory Appl, 161, 905 - 932.

R. Misener, J. Chin, M. Lai, M. Fuentes Garí, E. Velliou, N. Panoskaltsis, E.N. Pistikopoulos, A. Mantalaris, 2014a, Robust Superstructure Optimisation of a Bioreactor that Produces Red Blood Cells, in J. J. Kleměs, P. S. Varbanov, P. Y. Liew (Ed.), 24th European Symposium on Computer Aided Process Engineering. Vol. 33 of Computer-Aided Chemical Engineering. Budapest, Hungary; 91 - 96.

R. Misener, M. Fuentes Gari, M. Rende, E. Velliou, N. Panoskaltsis, E.N. Pistikopoulos, A. Mantalaris, 2014b, Global Superstructure Optimisation of Red Blood Cell Production in a Parallelised Hollow Fibre Bioreactor, Computers \& Chemical Engineering, 71, 532-553.

D.O. Morgan (2007) The cell cycle-Principles of control, New Sciences Press Ltd, London, UK.

T. Mortera-Blanco, A. Mantalaris, A. Bismarck, N. Panoskaltsis, 2010, Development of a three-dimensional biomimicry of human acute myeloid leukemia ex vivo, Biomaterials, 31, 2243-2251.

T. Mortera-Blanco, A. Mantalaris, A. Bismarck, N. Aqel, N. Panoskaltsis, 2011, Longterm cytokine-free expansion of cord blood mononuclear cells in three-dimensional scaffolds, Biomaterials, 32, 9263-9270.

T.T.A. Neildez-Nguyen, H. Wajcman, M.C. Marden, M. Bensidhoum, V.Moncollin, M.C. Giarratana, L. Kobairi, D. Thierry, L. Douay, 2002, Human erythroid cells produced ex vivo at large scale differentiate into red blood cells in vivo, Nature Biotechnology, 20, 5, 467-472. 
N. Panoskaltsis, A. Mantalaris, J.H.D. Wu, 2005, Engineering a mimicry of bone marrow tissue ex vivo, Journal of Bioscience and Bioengineering, 100, 1, 28-35.

N. Panoskaltsis, H.M. Macedo, T. Mortera-Blanco, A. Mantalaris, A.G. Livingston, 2012, 3D hollow fibre bioreactor systems for the maintenance, expansion, differentiation and harvesting of human stem cells and their progeny, Patent, WO 2012/069841 A1.

E. Pefani, N. Panoskaltsis, A. Mantalaris, M. C. Georgiadis, E. N. Pistikopoulos, 2013, Design of optimal patient-specific chemotherapy protocols for the treatment of acute myeloid leukemia (AML), Computers \& Chemical Engineering, 57, 187-195.

E. Pefani, N. Panoskaltsis, A. Mantalaris, M.C. Georgiadis, E.N. Pistikopoulos, 2014, Chemotherapy Drug Scheduling for the Induction Treatment of patients diagnosed with Acute Myeloid Leukemia, Transactions of Biomedical Engineering Journal, 61, 7, 2049-2056.

H.D. Preisler, Raza, A., V. Gopal, S. Ahmad, J. Bokhari, 1995, Distribution of cell cycle times amongst the leukemia cells within individual patients with acute myelogenous leukemia. Leukemia Research, 19, 10, 693-698.

P.J. Quesenberry, J.A. Colvin, 2001, Hematopoietic stem cells, progenitor cells, and cytokines, Hematology, McGraw-Hill, New York.

M. Rende, A. Mantalaris, R. Morilla, N. Aqel, N. Panoskaltsis, 2013, Biology Of Mixed Phenotype Acute Leukemia In Successful Long-Term Cytokine-Free ThreeDimensional (3D) Static and Perfused 3D Hollow-Fibre Bioreactor Culture, Blood, $122,21,2603$.

C.A.V. Rodrigues, T.G. Fernandes, M.M. Diogo, C. Lobato da Silva, J.M.S. Cabral, 2011, Stem cell cultivation in bioreactors, Biotechnology Advances, 29, 6, 815-829.

G.F. Rousseau, M.C. Giarratana, L. Douay, 2014, Large scale production of red blood cells from stem cells: What are the technical challenges ahead? Biotechnology Journal, 9, 28-38.

R. Saha, A. Chowdhury, C.D. Maranas, 2014, Recent Advances in the reconstruction of metabolic models and integration of omics data, Current Opinion in Biotechnology, 29, 39-45.

H. R. Tahhan, C. T. Holbrook, L. R. Braddy, L. D. Brewer, and J. D. Christie, 1994, Antigen-matched donor blood in the transfusion management of patients with sickle cell disease. Transfusion, 34, 7, 562-569.

N.E. Timmins, L.K. Nielsen, 2009, Blood cell manufacture: current methods and future challenges, Trends in Biotechnology, 27, 7, 415-422.

E. Velliou, S. Brito Dos Santos, M. Fuentes-Garí, R. Misener, N. Panoskaltsis, A. Mantalaris, E.N.Pistikopoulos, 2013, The effect of oxygen and glucose stress on the evolution of a leukemia model system in an in vitro bone marrow mimicry, 13th AIChE Annual Meeting, San Francisco, California, USA.

E. Velliou, S. Brito Dos Santos, M. Fuentes-Garí, R. Misener, N. Panoskaltsis, E.N. Pistikopoulos, A. Mantalaris, 2014 (a), Evolution of an AML model system under oxidative \& starvation stress: A comparison between two and three dimensional cultures, Journal of Tissue Engineering and Regenerative Medicine, 8, 489.

E. Velliou, S. Brito Dos Santos, M. Papathanasiou, M. Fuentes-Garí, R. Misener, N. Panoskaltsis, A. Mantalaris, E.N. Pistikopoulos 2014 (b) Towards unravelling the kinetics of an AML model system under oxidative and starvation stress: A comparison between two and three dimensional cultures (submitted).

E. Velliou, S. Brito Dos Santos, M. Fuentes-Garí, R. Misener, E. Pefani, N. Panoskaltsis, A. Mantalaris, E.N. Pistikopoulos 2014 (c) Key environmental stress 
biomarker candidates for the optimisation of chemotherapy treatment of leukaemia, Malta Journal of Health Sciences, 1, 2, 29 -34.

E. Velliou, S. Brito Dos Santos, M. Fuentes-Garí, R. Misener, N. Panoskaltsis, A. Mantalaris, E.N. Pistikopoulos 2014 (d), Towards in vitro optimisation of chemotherapy for leukaemia under environmental stress : Moving from two to three dimensional cultures, 14th AIChE Annual Meeting, Atlanta, Georgia, USA.

E. Velliou, M. Fuentes-Gari, R. Misener, E. Pefani, M. Rende, N. Panoskaltsis, E. N. Pistikopoulos, A. Mantalaris. 2014 (e), A framework for the design, modeling and optimization of biomedical systems. In Eden, Siirola, Towler (Ed.), 8th International Conference on Foundations of Computer-Aided Process Design. Computer-Aided Chemical Engineering. Cle Elum, WA, USA, 34, 225-236.

B.I. Whitaker, R.A. Henry, 2011, The 2011 Nationwide Blood Collection and Utilization Survey Report, Department of Health and Human Services, U.S.A.

Williams, W.J., Beutler, E., Erslev, A. J., Lichtman, M. A., 1983, Hematology. 3rd ed. USA: McGraw-Hill.

S. Zavitsanou, N. Panoskaltsis, A. Mantalaris, M.C. Georgiadis, E.N. Pistikopoulos, 2011, Modelling of the Insulin Delivery System for patients with Type 1 Diabetes Mellitus, 21st European Symposium on Computer Aided Process Engineering, 29, 1500-1504.

F.L. Zhou, W.G. Zhanh, Y.C. Wei, S. Meng, G.G. Bai-Wang, H.Y. Yang, W. Tian, X. Meng, H. Zhang, S.P. Chen, 2010, Involvement of oxidative stress in the relapse of acute myeloid leukemia, The Journal of Biological Chemistry, 285, 15010-15015. 


\section{Figure legends}

Figure 1: A framework for the design and optimization of biomedical systems (highlighted in orange with black arrows) and its application in the areas of artificial blood production (in green) and personalized leukemia treatments (in blue). In each example, scales are shown as rows, environments are shown as columns.

Figure 2: (a): Geometry of the 3D micro-bioreactor (b)-(c): Scanning Electron microscopy (SEM) images of the highly porous 3D micro-bioreactor including seeded leukemic cells.

Figure 3: (a) Diagram of blood-producing bioreactor (Macedo 2011); (b) Crosssection of a bioreactor (SEM); (c)(d) Krogh Cyclinder approximation; (e)

Poiseuille flow

Figure 4: Design of clinical treatment protocols for leukemia

Figure 5: Experimental design characteristics (input/output, duration, manpower) for (a) determination of parameters in 3D bioreactor; (b) extraction of cell cycle parameters for MS-PBM and for validation with phase distribution data; (c) characterization of metabolite effects on cellular growth in leukemia; (d) characterization of chemotherapeutic drug effects (Ara-C) on cellular growth and cell cycle evolution in leukemia.

Figure 6: K-562 growth in the 2D (a), (b) and the 3D (c), (d) system, at different oxygen levels: (a), (c) 20\% $\mathrm{O}_{2}$ and (b), (d) $5 \% \mathrm{O}_{2}$. Different colours represent different glucose levels: (®) $4.3 \mathrm{~g} / \mathrm{L}$ (control), (•) $1.3 \mathrm{~g} / \mathrm{L}$ (hyperglycemia), $(\bullet) 0.6 \mathrm{~g} / \mathrm{L}$ (hyperglycemia).

Figure 7: K-562 cell distribution in G0 and G1 phases of the cell cycle under oxidative and metabolic stress in the 2D culturing system. Different symbols represent different oxygen levels, i.e., Normoxia $\left(20 \% \mathrm{O}_{2}\right) \&$ - Hypoxia $\left(5 \% \mathrm{O}_{2}\right)$. Left panels Indicate hyperglycaemia, i.e., (a) \& (c) hyperglycaemia and right panels hypoglycaemia, i.e., (b) \& (d).

Figure 8: K-562 cell evolution (days 1-2) and survival (days 3-5) after $48 \mathrm{~h}$ exposure to $10 \mathrm{mg} / \mathrm{L} \mathrm{C}$-Ara at different oxygen levels: control (no exposure to drug), $\square 10 \mathrm{mg} / \mathrm{L} \mathrm{C}$-Ara 
Figure 1

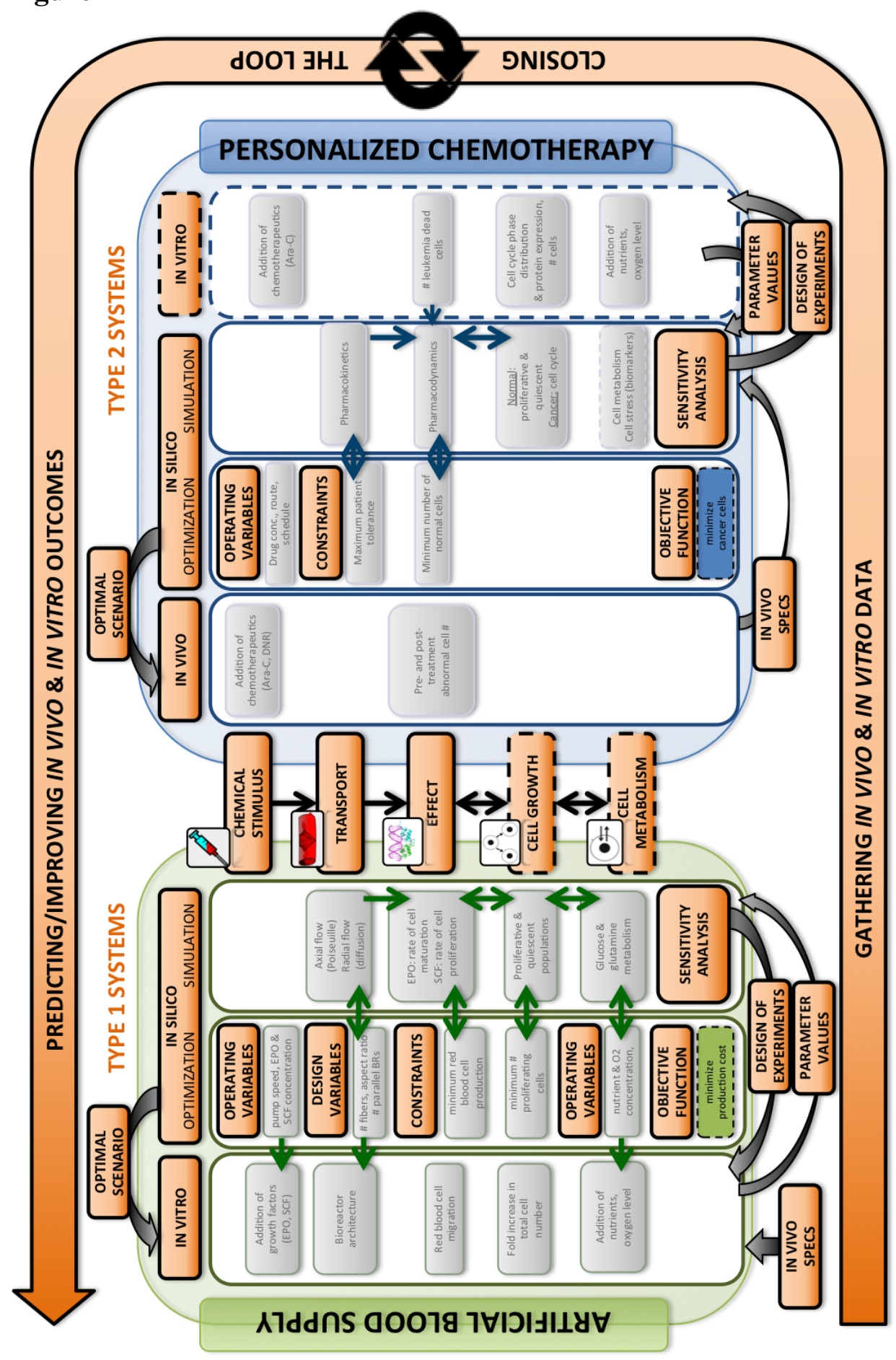


Figure 2
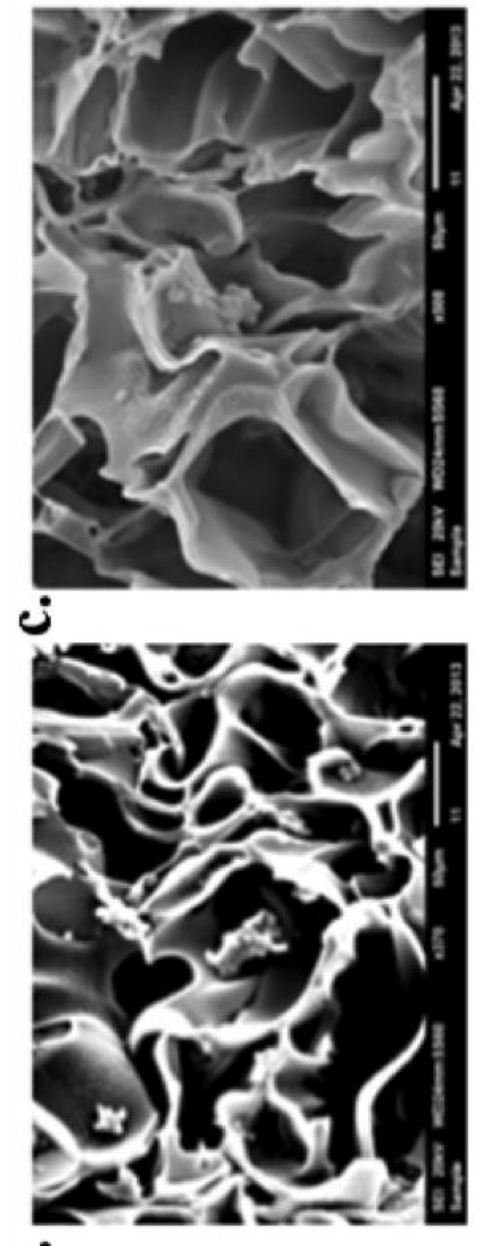

ம்

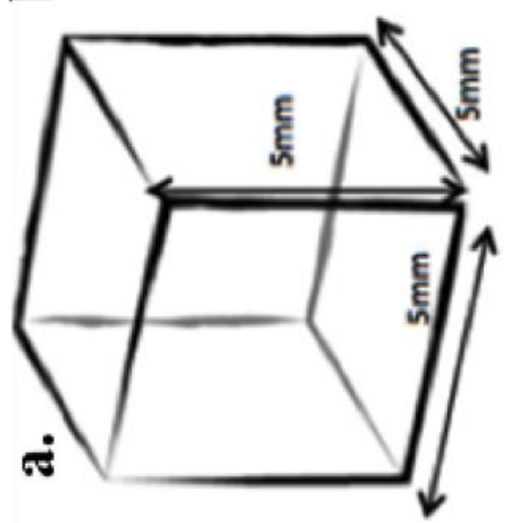


Figure 3
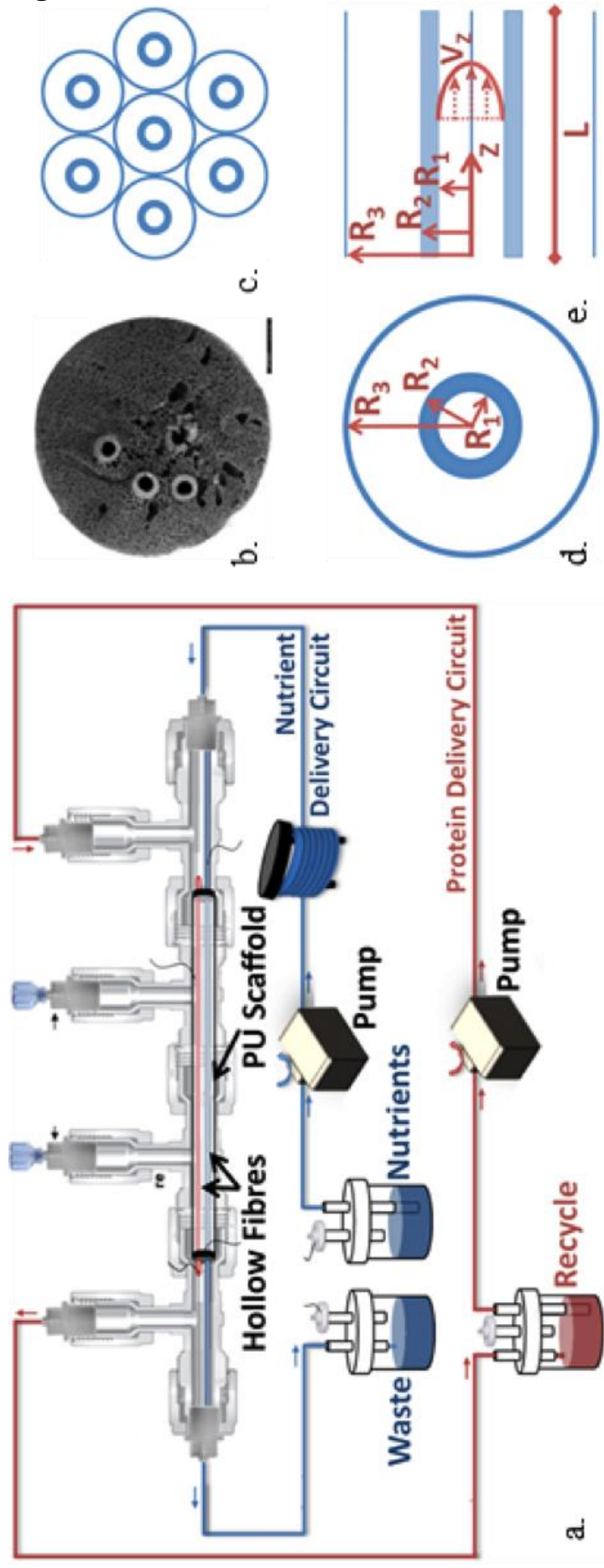
Figure 4

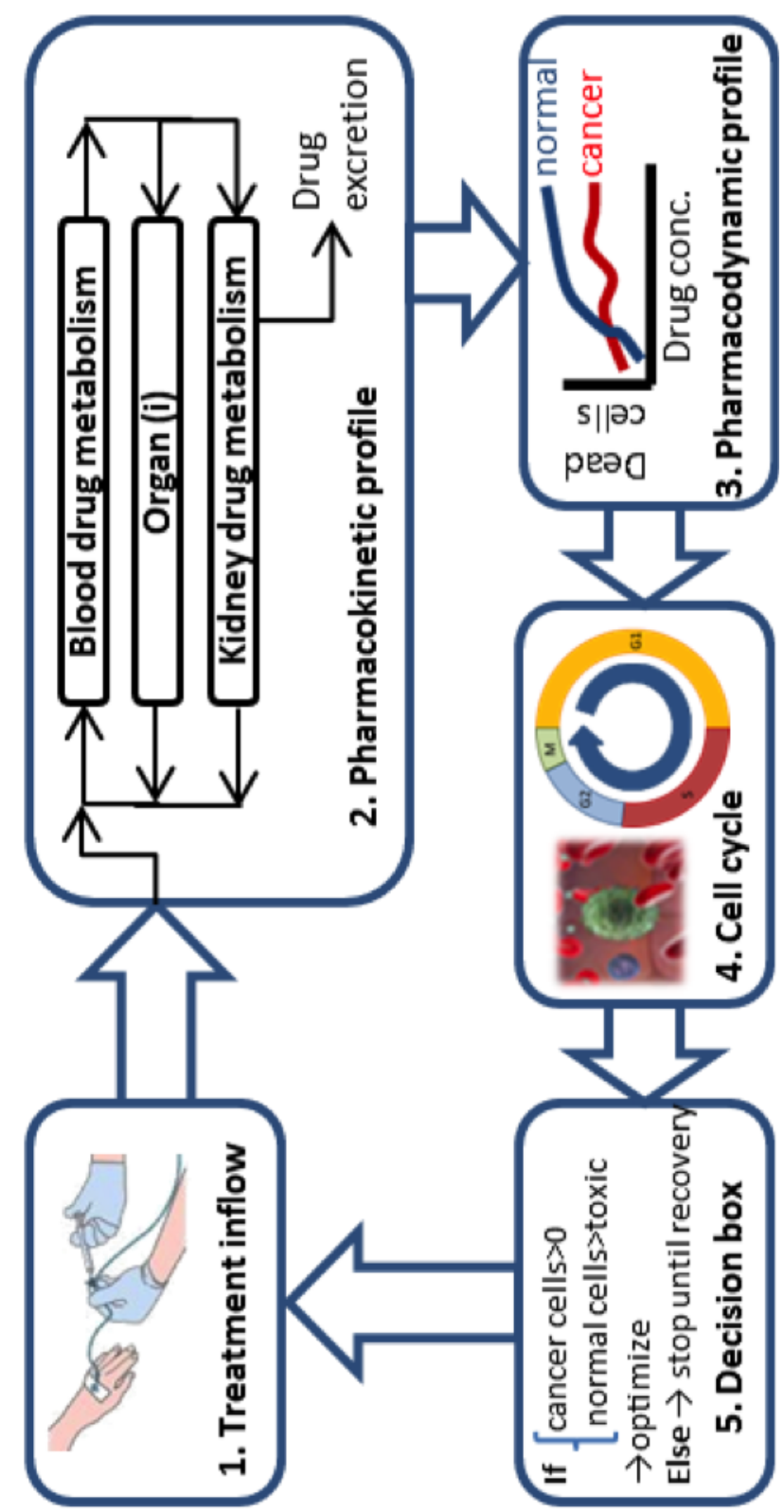


Figure 5

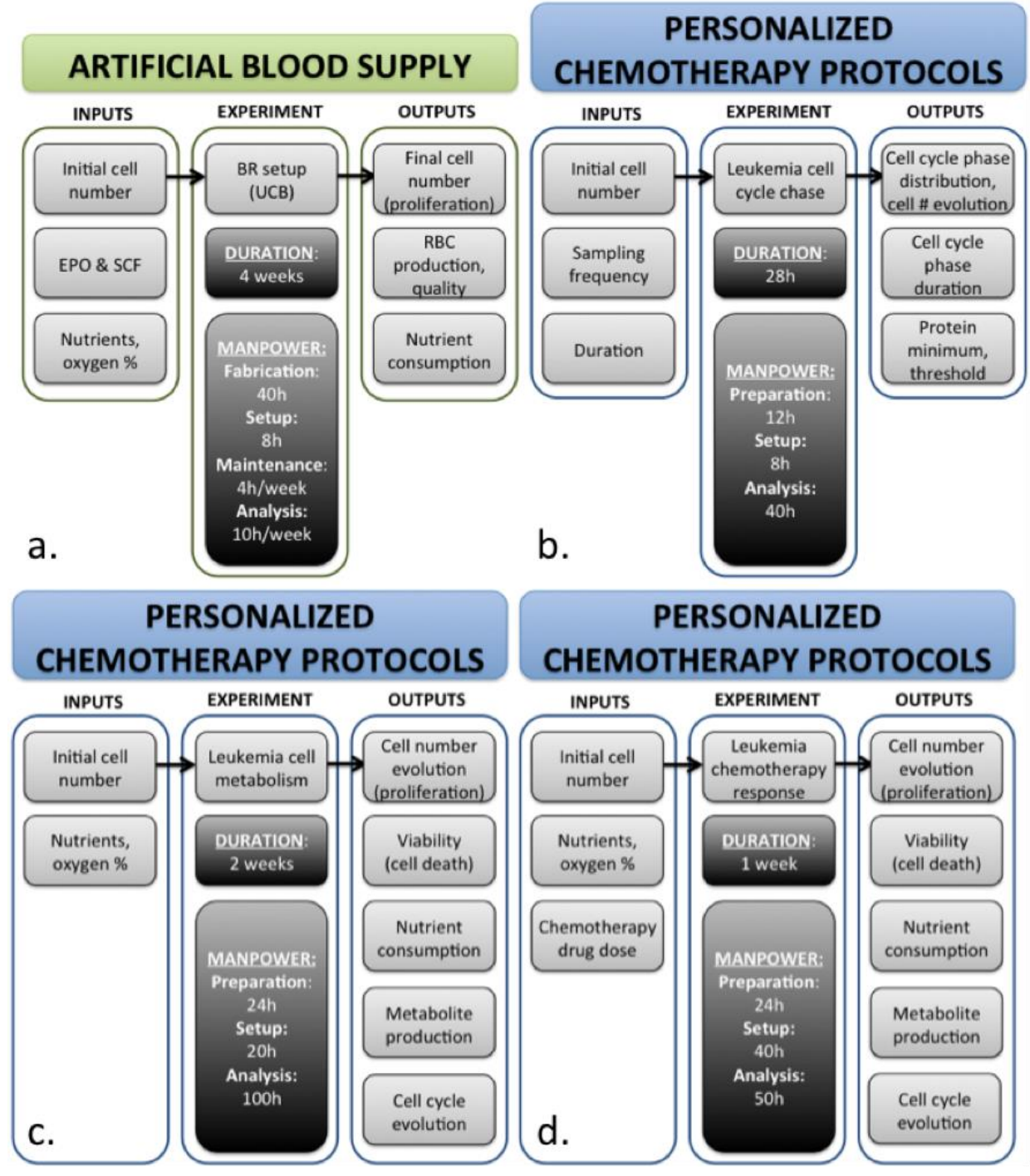


Figure 6
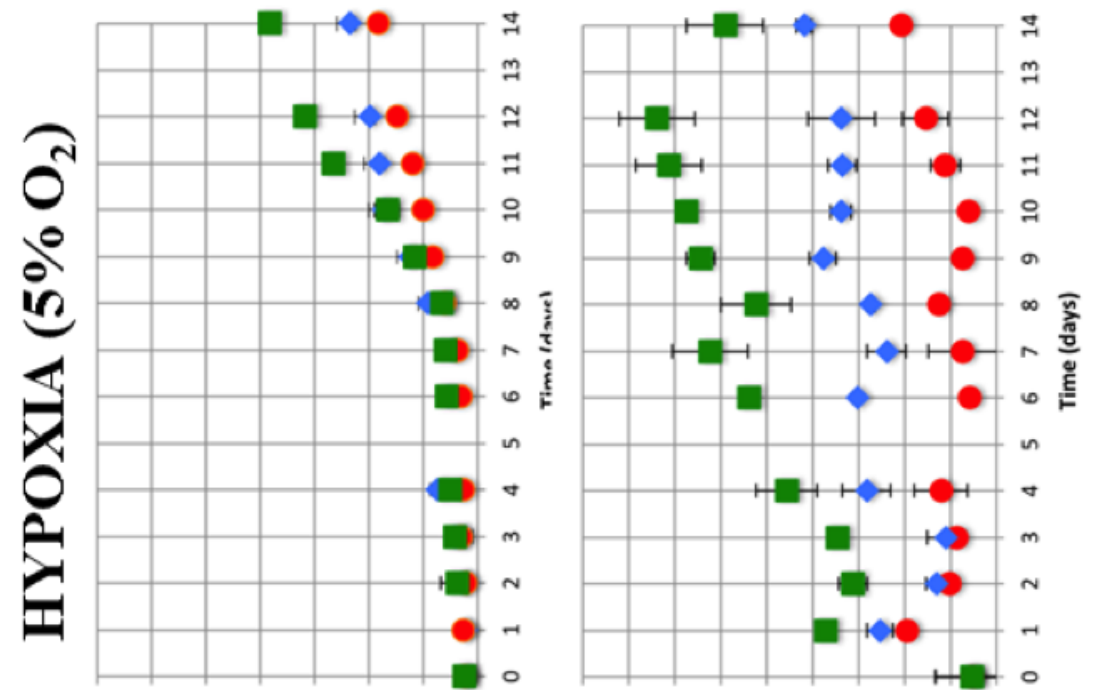

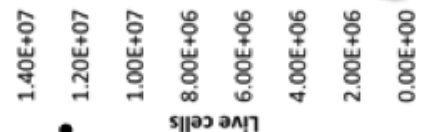

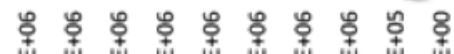

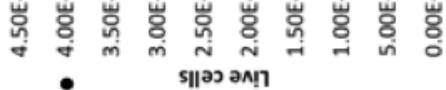

$\stackrel{\bullet}{\circ}$
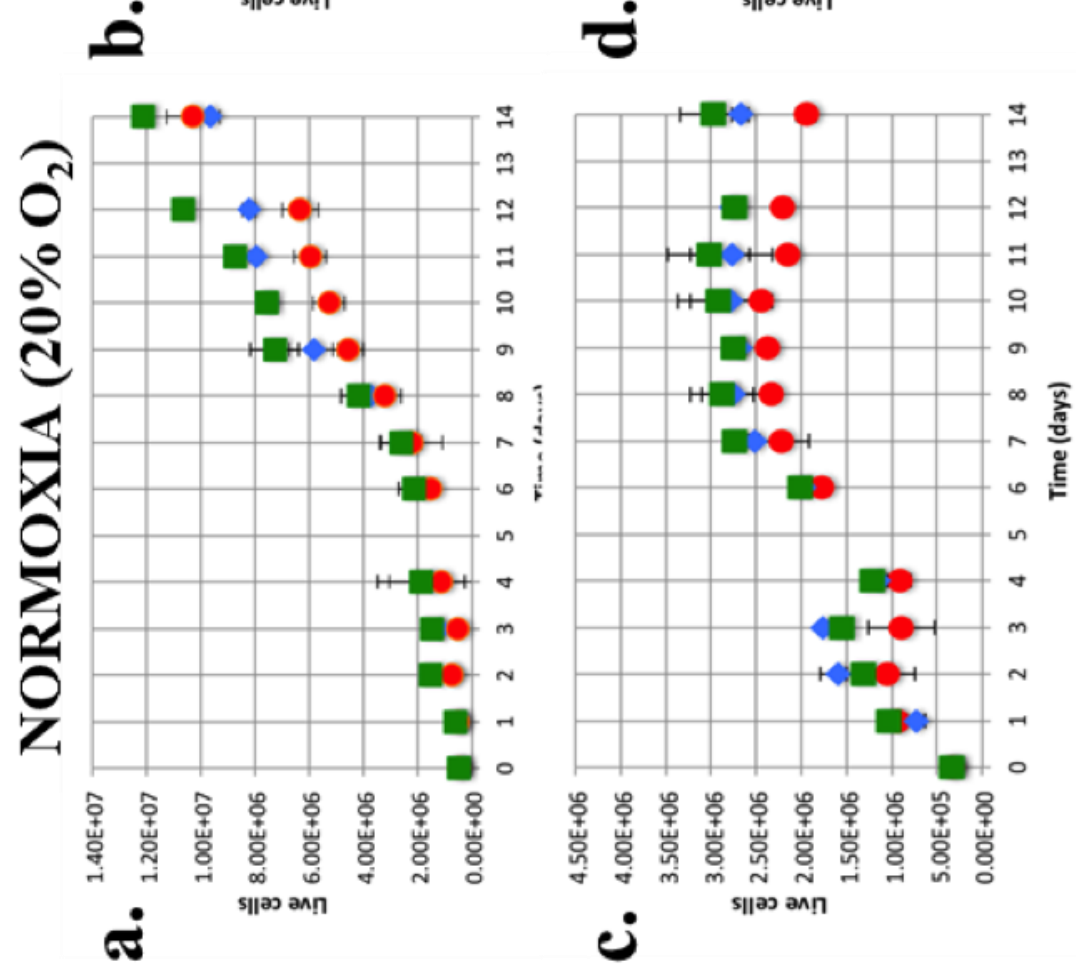

$\dot{\sigma}$ 
Figure 7

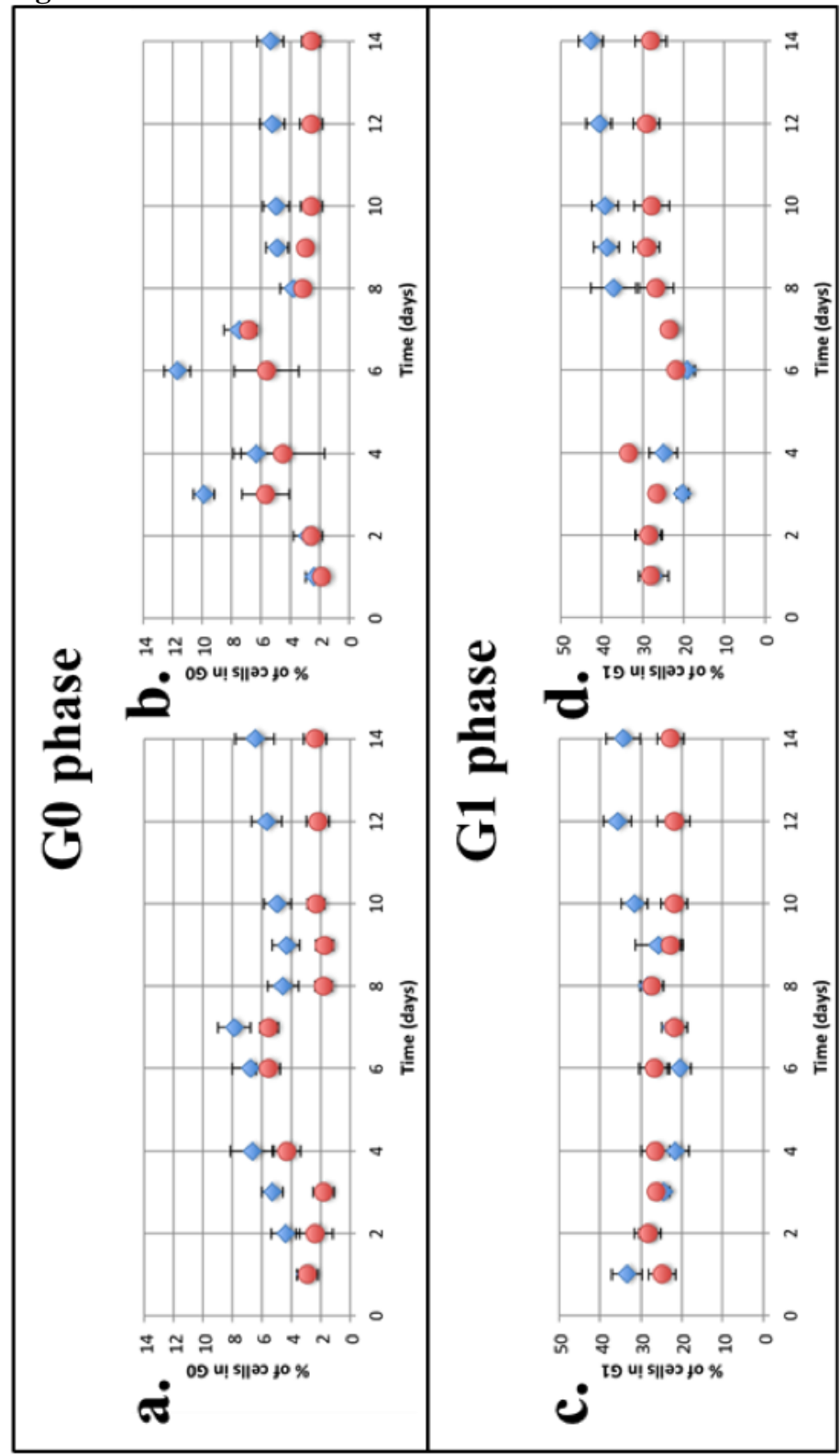


A systematic framework for the design, simulation and optimization of of personalized healthcare: making and healing blood

\section{Figure 8}

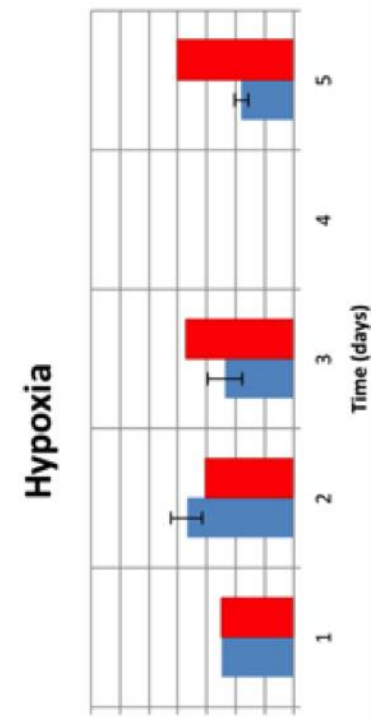

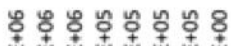

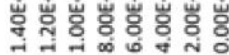

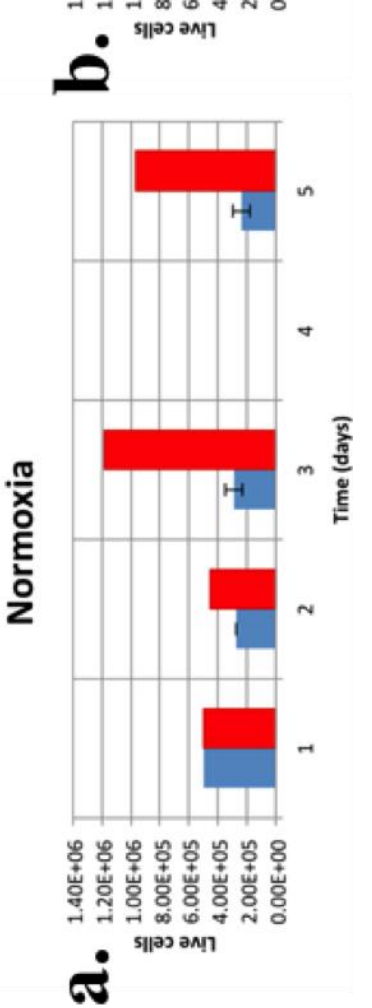




\section{Appendix}

1. Moving towards robust optimization in the blood-producing bioreactor

1.1. A first step is to consider which are the threshold values that are acceptable to operate the bioreactor experimentally.

1.2. At a second step, the model is analyzed using sensitivity analysis, providing the parameters that have the most influence on model output. In this case, the most influential was the cellular flux across ceramic hollow fibers, followed by SCF half-life and cost, cellular differentiation and metabolism specific parameters, EPO half-life and price, and hollow fiber porosity.

1.3. At a third step, the main sources of uncertainty in the model have to be identified. For the bioreactor, these are (1) species reaction rate; (2) cellular proliferation and differentiation rate; (3) exit rate of mature cells from the bioreactor.

The optimization problem and a table of parameters are given below:

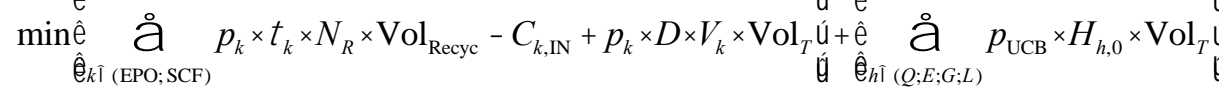

s.t.

Superstructure topology:

$N_{\mathrm{HF}}=N_{\mathrm{HF}, \mathrm{PAN}}+N_{\mathrm{HF}, \mathrm{CRM}}$

${ }_{\mathrm{R}, \mathrm{HF}} \times R_{4}^{2} \quad N_{\mathrm{HF}, \mathrm{PAN}} \times R_{2, \mathrm{PAN}}^{2}+N_{\mathrm{HF}, \mathrm{CRM}} \times R_{2, \mathrm{CRM}}^{2}$

$\mathrm{Vol}_{R}=\left(\begin{array}{ll}L & L_{e}\end{array}\right) R_{4}^{2} \quad N_{\mathrm{HF}, \mathrm{PAN}} \times R_{2, \mathrm{PAN}}^{2} \quad N_{\mathrm{HF}, \mathrm{CRM}} \times R_{2, \mathrm{CRM}}^{2}$

$\frac{\left(\begin{array}{ll}L & L_{e}\end{array}\right) \times R_{4}^{2}}{N_{\mathrm{HF}, \mathrm{PAN}}} \quad k=\mathrm{Glc}, \mathrm{Lac}$

$\mathrm{Vol}_{K, k}=\frac{\left(\begin{array}{ll}L & L_{e}\end{array}\right) \times R_{4}^{2}}{N_{\mathrm{HF}, \mathrm{PAN}}+N_{\mathrm{HF}, \mathrm{CRM}}} \quad k=\mathrm{O}_{2}$

$\frac{\left(L L_{e}\right) \times R_{4}^{2}}{N_{\mathrm{HF}, \mathrm{CRM}}} \quad k=\mathrm{EPO}, \mathrm{SCF}$

$R_{3, k}=\sqrt{\frac{\mathrm{Vol}_{K, k}}{\left(\begin{array}{ll}L & L_{e}\end{array}\right)}} \quad k$

$\mathrm{Vol}_{T}=N_{R} \times \mathrm{Vol}_{R}$ 
Production requirement:

$$
\begin{aligned}
H_{Q, t}+H_{L, t}+H_{E, t}+H_{G, t} & H_{\mathrm{MAX}} \\
P, t & =J_{\mathrm{Cells}, t} \times \times N_{\mathrm{HF}, \mathrm{CRM}} \times R_{2, \mathrm{CRM}} \times L \quad t \quad\{1, \ldots, 5\} \\
{ }_{P, t} D_{t} H_{E, t} \quad \mathrm{Unit}_{\mathrm{RBC}} &
\end{aligned}
$$

\section{Species transfer:}

$C_{k, \mathrm{MIN}} C_{k, i(r, z)} \quad C_{k, \mathrm{MAX}} \quad i, k$

$C_{k, \text { OUT }}=R_{2} \frac{R_{1}^{2}}{R_{2}} \div \times \frac{N_{\mathrm{HF}} \times V_{k}}{U_{Z}} \div+C_{k, \mathrm{IN}} \quad k$

$C_{k, \mathrm{LOSS}}=\frac{V_{k}}{D_{k, 3}}\left(R_{3}^{2} \quad R_{2}^{2}\right) \times \frac{11}{48}+\frac{1}{2 \times e_{\mathrm{HF}}} \ln \frac{R_{2}}{R_{1}} \div \quad k$

$C_{k, 3}\left(R_{2}, 0\right)=C_{k, \mathrm{IN}} \quad C_{k, \mathrm{LOSS}} \quad k$

$C_{k, 3}\left(R_{3}, L\right)=\frac{V_{k}}{D_{k, 3}} \frac{R_{3}^{2}}{2} \ln \frac{R_{3}}{R_{2}} \frac{R_{3}^{2} R_{2}^{2}}{4} \div+C_{k, \text { OUT }} \quad C_{k, \text { LOSS }} \quad k$

Proliferation \& differentiation:

$$
\begin{aligned}
& \frac{H_{Q, t} \quad H_{Q, t 1}}{t}=\left({ }_{E, t 11}+{ }_{G, t 1}+{ }_{L, t 1}\right) \cdot H_{Q, t 1}+\left(2 \cdot e^{s \cdot Q} 1\right) . \\
& C_{k, \mathrm{MIN}} \leq C_{k, i(r, z)} \leq C_{k, \mathrm{MAX}} \quad i, k \\
& C_{k, \mathrm{OUT}}=\left(R_{2} \frac{R_{1}^{2}}{R_{2}}\right) \cdot\left(\frac{N_{\mathrm{HF}} \cdot V_{k}}{U_{Z}}\right)+C_{k, \mathrm{IN}} \quad k \\
& C_{k, \mathrm{LOSS}}=\frac{V_{k}}{D_{k, 3}}\left(R_{3}^{2} \quad R_{2}^{2}\right) \cdot\left(\frac{11}{48}+\frac{1}{2 \cdot e_{\mathrm{HF}}} \ln \frac{R_{2}}{R_{1}}\right) k \\
& C_{k, 3}\left(R_{2}, 0\right)=C_{k, \mathrm{IN}} C_{k, \mathrm{LOSS}} \quad k \\
& C_{k, 3}\left(R_{3}, L\right)=\frac{V_{k}}{D_{k, 3}}\left(\frac{R_{3}^{2}}{2} \ln \frac{R_{3}}{R_{2}} \frac{R_{3}^{2} R_{2}^{2}}{4}\right)+C_{k, \text { OUT }} C_{k, \mathrm{LOSS}} k
\end{aligned}
$$




\begin{tabular}{|c|c|c|c|}
\hline & Symbol & Description & Units \\
\hline \multirow{8}{*}{ 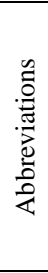 } & BM & Bone marrow & \\
\hline & $\mathrm{HF}$ & Hollow fiber & \\
\hline & HFMB & Hollow fiber membrane bioreactor & \\
\hline & HSC & Haematopoietic stem cell & \\
\hline & PAN & Polyacrilonitrile & \\
\hline & $\mathrm{PU}$ & Polyurethane & \\
\hline & RBC & Erythrocyte, red blood cell & \\
\hline & $\mathrm{UCB}$ & Umbilical cord blood & \\
\hline \multirow{4}{*}{ 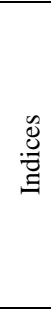 } & $h$ & $\begin{array}{r}\text { Haematopoietic cells; } h \in\{Q, E, L, G\} \text { where } \quad Q \equiv \mathrm{HSC}, E \equiv \mathrm{RBC} \\
L \equiv \text { lymphocytes, } G \equiv \text { granulocytes }\end{array}$ & \\
\hline & $i$ & 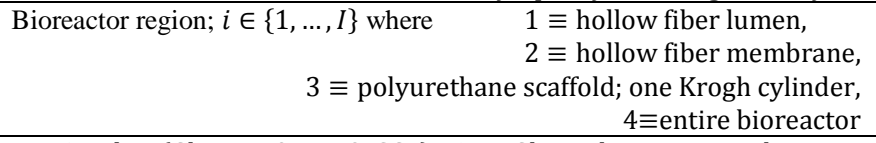 & \\
\hline & $k$ & $\begin{array}{r}\text { Species; } k \in\left\{\mathrm{Glc}, \mathrm{Lac}, \mathrm{O}_{2}, \mathrm{EPO}, \mathrm{SCF}\right\} \text { where Glc } \equiv \text { glucose, Lac } \equiv \text { lactate, } \\
\mathrm{O}_{2} \equiv \text { oxygen, } \mathrm{EPO} \equiv \text { erythropoietin, } \mathrm{SCF} \equiv \text { stem cell factor }\end{array}$ & \\
\hline & $t$ & Time period in weeks; $t \in\{1, \ldots, 5\}$ & \\
\hline \multirow{8}{*}{ 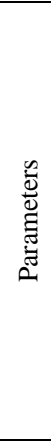 } & $\mathrm{C}_{\mathrm{k}, \mathrm{MIN}}$ & Allowable concentration range of species $k$ & \\
\hline & $\mathrm{C}_{\mathrm{k}, \operatorname{MAX}}$ & $\mathrm{C}_{\mathrm{Glc}}, \mathrm{C}_{\mathrm{Lac}}, \mathrm{C}_{O_{2}}[=] \frac{\mathrm{mol}}{\mathrm{m}^{3}}, \mathrm{C}_{\mathrm{EPO}}[=] \frac{\mathrm{U}}{\mathrm{m}^{3}}, \mathrm{C}_{\mathrm{SCF}}[=] \frac{\mathrm{mg}}{\mathrm{m}^{3}}$ & \\
\hline & $\mathrm{D}$ & Days at steady state culture conditions & 35 days \\
\hline & $\epsilon_{R, H F}$ & Maximum HF packing density in reactor & 0.14 \\
\hline & $H_{\mathrm{MAX}}$ & Maximum cell density & $\begin{array}{l}0.5 \times 10^{-6} \\
\text { cells } / \mathrm{mm}^{3}\end{array}$ \\
\hline & $\mathrm{R}_{i}$ & $\begin{array}{cc}\text { Radius of region } i \in\{1,2\} & \mathrm{R}_{\mathrm{CRM}, 1}=0.25 \mathrm{~mm} ; \mathrm{R}_{\mathrm{CRM}, 2}=0.43 \mathrm{~mm} \\
& \mathrm{R}_{\mathrm{PAN}, 1}=0.26 \mathrm{~mm} ; \mathrm{R}_{\mathrm{PAN}, 2}=0.45 \mathrm{~mm} \\
\end{array}$ & \\
\hline & Unit $_{\mathrm{RBC}}$ & Number of RBC in one unit & $\begin{array}{l}2 \times 10^{12} \\
\text { cells }\end{array}$ \\
\hline & Vol $_{\text {Recyc }}$ & Recycle volume needed for each reactor & $\begin{array}{l}1.0 \times 10^{-4} \\
\mathrm{~m}^{3}\end{array}$ \\
\hline \multirow{12}{*}{ 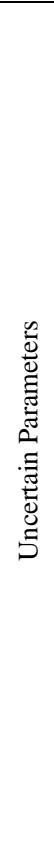 } & $\mathrm{A}_{h}$ & $\begin{array}{l}\text { Amplification parameter for differentiation } h \in\{E, L, G\} \\
\qquad \mathrm{A}_{\mathrm{E}}=5.63 \times 10^{5} ; \mathrm{A}_{\mathrm{G}}=2.82 \times 10^{5} ; \mathrm{A}_{\mathrm{L}}=7.52 \times 10^{4}\end{array}$ & \\
\hline & $\mathrm{D}_{k, i}$ & Diffusivity of species $k$ in region $i \in\{1,2,3\}$ & $\mathrm{m}^{2} / \mathrm{s}$ \\
\hline & $\epsilon_{\mathrm{PU}} ; \epsilon_{\mathrm{HF}}$ & Porosity of HF and PU scaffold & \\
\hline & $\gamma_{h}$ & $\begin{array}{l}\text { Death rate (non-age) of differentiated cells; } h \in\{E, L, G\} \\
\qquad \gamma_{\mathrm{E}}=0.001 \text { days }^{-1} ; \gamma_{\mathrm{G}}=0.15 \text { days }^{-1} ; \gamma_{\mathrm{L}}=2.4 \text { days }^{-1}\end{array}$ & \\
\hline & $\gamma_{Q}$ & Death rate of HSC during proliferation & 0.1 days $^{-1}$ \\
\hline & $\hat{J}_{\text {Cells }}$ & $\begin{array}{l}\text { Cellular flux across ceramic } \mathrm{HF} \text { when } \Delta \widehat{H}_{\text {Cells }}=1.0 \times 10^{6} \text { cells } / \mathrm{mm}^{3} \\
\hat{J}_{\text {Cells }}=5.76 \pm 2.25 \times 10^{5} \text { cells } / \mathrm{mm}^{2} / \text { day }\end{array}$ & \\
\hline & $\mathrm{p}_{k}$ & $\mathrm{p}_{\mathrm{EPO}}=0.023 \mathrm{US} \$ / \mathrm{U} ; \mathrm{p}_{\mathrm{SCF}}=320 \mathrm{US} \$ / \mathrm{mg}$ & \\
\hline & $\mathrm{p}_{\text {UCB }}$ & Price of umbilical cord blood & $\begin{array}{l}\text { US } \$ 220 \\
/ 4 \times 10^{8} \\
\text { nucleated } \\
\text { cells }\end{array}$ \\
\hline & $\mathrm{t}_{1 / 2, k}$ & $\mathrm{t}_{1 / 2, \mathrm{EPO}}=3$ days; $\mathrm{t}_{1 / 2, \mathrm{SCF}}=2$ days & \\
\hline & $\tau_{Q}$ & Stem cell proliferation time & 1.4 days \\
\hline & $V_{k}$ & $\begin{array}{l}\text { Maximum reaction rate of species } k \text { in the scaffold } \\
\qquad \mathrm{V}_{\mathrm{Gl}}, \mathrm{V}_{\mathrm{Lac}}, \mathrm{V}_{\mathrm{O}_{2}}[=] \frac{\mathrm{mol}}{\mathrm{m}^{3} \mathrm{day}}, \mathrm{V}_{\mathrm{EPO}}[=] \frac{\mathrm{U}}{\mathrm{m}^{3} \text { day }}, \mathrm{V}_{\mathrm{SCF}}[=] \frac{\mathrm{mg}}{\mathrm{m}^{3} \mathrm{day}}\end{array}$ & \\
\hline & $V_{O_{2}, k}$ & $\begin{array}{l}\text { Reaction rate of } \mathrm{O}_{2} \text { with cell type } h \text { in the scaffold } \\
\qquad \mathrm{V}_{O_{2}, \mathrm{HSC}}=3.89 \times 10^{-14} \frac{\mathrm{mol}}{\text { cell day }} ; \mathrm{V}_{O_{2}, \mathrm{RBC}}=1.56 \times 10^{-13} \frac{\mathrm{mol}}{\text { cell day }} \\
\qquad \mathrm{V}_{O_{2} \text {, Gran }}=1.56 \times 10^{-11} \frac{\mathrm{mol}}{\text { cell day }} ; \mathrm{V}_{O_{2}, \text { Gran }}=1.2 \times 10^{-12} \frac{\mathrm{mol}}{\text { cell day }}\end{array}$ & \\
\hline
\end{tabular}


A systematic framework for the design, simulation and optimization of of personalized healthcare: making and healing blood

\begin{tabular}{|c|c|c|c|}
\hline \multirow{8}{*}{ 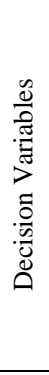 } & $C_{k, \mathrm{IN}}$ & $\begin{array}{l}\text { Conc. of species } k \text { at bioreactor inlet } \\
\qquad \mathrm{C}_{\mathrm{Glc}, \mathrm{IN}}, \mathrm{C}_{\mathrm{Lac}, \mathrm{IN}}, \mathrm{C}_{\mathrm{O}_{2}, \mathrm{IN}}[=] \frac{\mathrm{mol}}{\mathrm{m}^{3}}, \mathrm{C}_{\mathrm{EPO}, \mathrm{IN}}[=] \frac{\mathrm{U}}{\mathrm{m}^{3}}, \mathrm{C}_{\mathrm{SCF}, \mathrm{IN}}[=] \frac{\mathrm{mg}}{\mathrm{m}^{3}}\end{array}$ & \\
\hline & $L$ & $\hat{L}=150 \mathrm{~mm} ; L \in[50 \mathrm{~mm}, 200 \mathrm{~mm}]$ & \\
\hline & $\mathrm{N}_{\mathrm{HF}}$ & Number of hollow fibers & \\
\hline & $\mathrm{N}_{\mathrm{HF}, \mathrm{CRM}}$ & $\widehat{\mathrm{N}}_{\mathrm{HF}, \mathrm{CRM}}=4 ; \mathrm{N}_{\mathrm{HF}, \mathrm{CRM}} \in\{1, \ldots, 20\}$ & \\
\hline & $\mathrm{N}_{\mathrm{HF}, \text { PAN }}$ & $\widehat{\mathrm{N}}_{\mathrm{HF} \text { PAN }}=4 ; \mathrm{N}_{\mathrm{HF}, \text { PAN }} \in\{1, \ldots, 20\}$ & \\
\hline & $\mathrm{N}_{R}$ & Number of equivalent bioreactors & \\
\hline & $\mathrm{R}_{4}$ & $\widehat{\mathrm{R}}_{4}=3.75 \mathrm{~mm} ; \mathrm{R}_{4} \in[2,10]$ & \\
\hline & $U_{Z}$ & $\begin{array}{l}\text { Bulk liquid velocity in the HF } \widehat{U}_{Z}=7.1 \times 10^{-2} \mathrm{~mm} / \mathrm{s} ; U_{Z} \in \\
{\left[\widehat{U}_{Z}, 2 \cdot \widehat{U}_{Z}\right]}\end{array}$ & \\
\hline \multirow{15}{*}{ 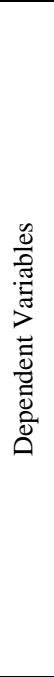 } & $\beta_{Q, t}$ & Rate of entry into the proliferative phase & days $^{-1}$ \\
\hline & $C_{k, i}(\mathrm{r}, \mathrm{z})$ & $\begin{array}{l}\text { Conc. of species } k \text { in region } i \text { at location }(\mathrm{r}, \mathrm{z}) \\
\mathrm{C}_{\mathrm{Glc}, \mathrm{i}}(\mathrm{r}, \mathrm{z}), \mathrm{C}_{\mathrm{Lac}, \mathrm{i}}(\mathrm{r}, \mathrm{z}), \mathrm{C}_{\mathrm{O}_{2}, i}(\mathrm{r}, \mathrm{z})[=] \frac{\mathrm{mol}}{\mathrm{m}^{3}}, \mathrm{C}_{\mathrm{EPO}, \mathrm{i}}(\mathrm{r}, \mathrm{z})[=] \frac{\mathrm{U}}{\mathrm{m}^{3}}, \mathrm{C}_{\mathrm{SCF}, \mathrm{i}}(\mathrm{r}, \mathrm{z})[=] \frac{\mathrm{mg}}{\mathrm{m}^{3}}\end{array}$ & \\
\hline & $C_{k, \text { OUT }}$ & $\begin{array}{l}\text { Conc. of species } k \text { at bioreactor outlet } \\
\qquad \mathrm{C}_{\mathrm{Glc} \text {, OUT }}, \mathrm{C}_{\mathrm{Lac} \text {, ouT }}, \mathrm{C}_{\mathrm{O}_{2} \text {, OUT }}[=] \frac{\mathrm{mol}}{\mathrm{m}^{3}}, \mathrm{C}_{\mathrm{EPO} \text {, oUT }}[=] \frac{\mathrm{U}}{\mathrm{m}^{3}}, \mathrm{C}_{\mathrm{SCF} \text {, ouT }}[=] \frac{\mathrm{mg}}{\mathrm{m}^{3}}\end{array}$ & \\
\hline & $\gamma_{P, t}$ & Production rate of cells from the bioreactor & days $^{-1}$ \\
\hline & $H_{h, t}$ & Cell types $h \in\{Q, E, L, G\}$ in region 3 for $t \in\{1, \ldots, 5\}$ & cells $/ \mathrm{m}^{3}$ \\
\hline & $J_{\text {Cells }}$ & Cellular flux across ceramic HF & \\
\hline & $\kappa_{h, t}$ & Differentiation rate towards committed lineages $h \in\{E, L, G\}$ & days $^{-1}$ \\
\hline & $\mathrm{R}_{3}$ & Radius of region $i \in\{3\}$ & $\mathrm{mm}$ \\
\hline & $\mathrm{r}$ & Radial distance from center of Krogh cyclinder & $\mathrm{mm}$ \\
\hline & $\operatorname{Rxn}_{k}$ & $\begin{array}{l}\text { Reaction rate of species } k ; 0^{\text {th }} \text {-order approx } \\
\qquad \operatorname{Rxn}_{\mathrm{Glc}}, \operatorname{Rxn}_{\mathrm{Lac}}, \operatorname{Rxn}_{\mathrm{O}_{2}}[=] \frac{\mathrm{mol}}{\mathrm{m}^{3} \text { day }}, \operatorname{Rxn}_{\mathrm{EPO}}[=] \frac{\mathrm{U}}{\mathrm{m}^{3} \text { day }}, \operatorname{Rxn}_{\mathrm{SCF}}[=] \frac{\mathrm{mg}}{\mathrm{m}^{3} \text { day }}\end{array}$ & \\
\hline & $\tau_{k}$ & Rate for replenishing growth factor & - \\
\hline & $\mathrm{Vol}_{K, k}$ & Krogh volume for each species $k \in\left\{\right.$ Glc, Lac, $\left.\mathrm{O}_{2}, \mathrm{EPO}, \mathrm{SCF}\right\}$ & $\mathrm{m}^{3}$ \\
\hline & $\mathrm{Vol}_{R}$ & Reactor volume & $\mathrm{m}^{3}$ \\
\hline & $\mathrm{Vol}_{T}$ & Total volume & $\mathrm{m}^{3}$ \\
\hline & $\mathrm{Z}$ & Axial distance along the bioreactor & $\mathrm{mm}$ \\
\hline
\end{tabular}




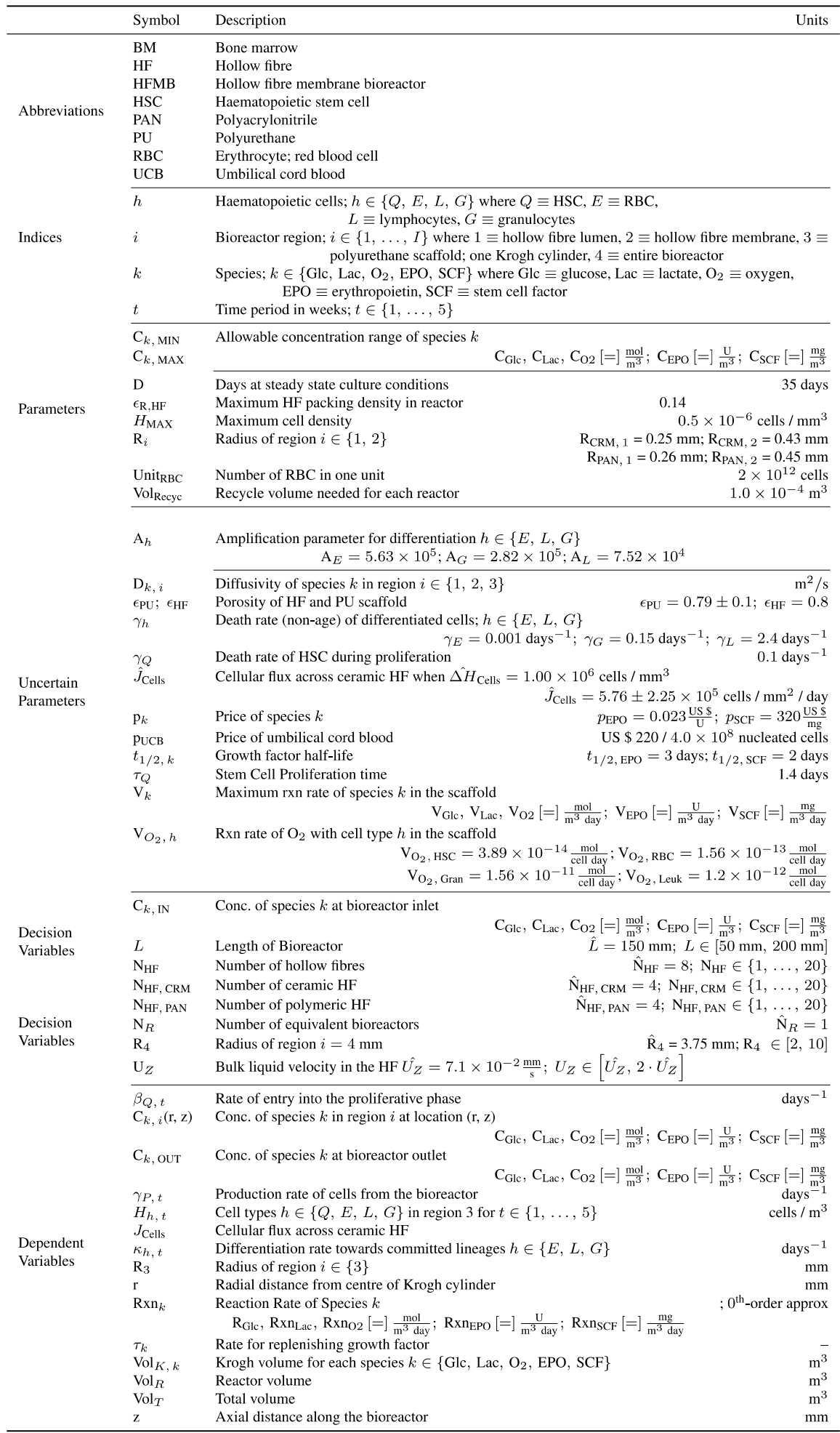


2. Model equations

2.1. Pharmacokinetics (Pefani et al., 2013)

\begin{tabular}{|c|c|}
\hline $\begin{array}{l}\text { Drug transport } \\
\text { in blood }\end{array}$ & $\begin{array}{l}V_{B} \times \frac{d C_{B, j}}{d t}=Q_{\substack{i: H, L i, M, L e \\
j: a r a}, D N R} \times C_{i, j}+Q_{K} \times C_{K, j} \quad Q_{B} \times C_{B, j}+I n_{j} \\
\text { where: } \\
V_{B}: \text { volume of blood } \\
C_{B, j}: \text { concentration of drug } j \text { in the blood } \\
Q_{i}: \text { blood flow in organ } i \\
Q_{K}: \text { blood flow in kidneys } \\
Q_{B}: \text { blood flow in blood } \\
C_{K, j}: \text { concentration of drug } j \text { in kidneys } \\
C_{i, j}: \text { concentration of drug } j \text { in organ } i \\
I n_{j}: \text { inflow rate of infusion }(\mathrm{mg} / \mathrm{h})\end{array}$ \\
\hline $\begin{array}{l}\text { Drug excretion } \\
\text { by other organs } \\
\text { (i) }\end{array}$ & $\begin{array}{l}V_{i} \times \frac{d C_{i, j}}{d t}=Q_{i} \times C_{B, j} \quad Q_{i} \times C_{i, j} \quad k_{K, j} \times C_{B, j} \times V_{i, T} \\
\text { where: } \\
V_{j}: \text { volume of organ } i \\
C_{i, j}: \text { concentration of drug } j \text { in organ } i \\
Q_{i}: \text { blood flow in organ } i \\
C_{B, j}: \text { concentration of drug } j \text { in blood compartment } \\
k_{K, j}: \text { drug clearance rate by the kidneys } \\
V_{i, T}: \text { volume of organ tissue }\end{array}$ \\
\hline $\begin{array}{l}\text { Cumulative drug } \\
\text { excretion }\end{array}$ & $\begin{array}{l}U_{j}={ }^{t} k_{K, j} \times C_{\mathbb{B}_{r j}} d t \\
\text { where: } \\
U_{j}: \text { cumulative drug excretion } \\
k_{K, j}: \text { drug clearance rate by the kidneys } \\
C_{B, j}: \text { concentration of drug } j \text { in blood compartment }\end{array}$ \\
\hline Inflow drug dose & $\begin{array}{l}\operatorname{In}_{j}=\frac{\text { dose }_{j}}{\text { duration }_{j}} \\
\text { where: } \\
I_{j}: \text { inflow rate of infusion }(\mathrm{mg} / \mathrm{h}) \\
\text { dose }_{j}: \text { clinical dose administered to patient }(\mathrm{mg}) \\
\text { duration }_{j}: \text { duration of the infusion of drug } j\end{array}$ \\
\hline
\end{tabular}




\begin{tabular}{|l|l|}
\hline $\begin{array}{l}\text { Clinical practice } \\
\text { drug dose } \\
\text { calculation }\end{array}$ & dose $_{j}=u_{j} \times b s a \quad b s a=\sqrt{\frac{h e i g h t \times \text { weight }}{3600}}$ \\
& where: \\
& $\begin{array}{l}\text { dose } e_{j}: \text { clinical dose administered to patient }(\mathrm{mg}) \\
u_{j}: \text { drug dose in } \mathrm{mg} / \mathrm{m} 2(\operatorname{drug} j) \\
\\
b s a: \text { body surface area } \\
\\
\text { height, weight: actual height and weight of the patient }\end{array}$ \\
\hline
\end{tabular}

2.2. Pharmacodynamics (Pefani et al., 2013)

\begin{tabular}{|l|l|}
$\begin{array}{l}\text { Drug effect on } \\
\text { cell cycle phase }\end{array}$ & effect $_{y, j}=\frac{E_{\text {max }, y, j} \times C_{M, y, j}^{\text {slope }}}{E_{50, y, j}+C_{M, y, j}^{s l o p e}}$ \\
& where: \\
& $E_{m a x, y, j}:$ maximum drug effect \\
& $E_{50, y, j}:$ concentration at half-drug effect (drug $\left.j\right)$ \\
& $C_{M, y, j}:$ concentration of drug $j$ at the location of the tumor \\
& slope: scaling factor for DNR drug action \\
& effect $t_{y, j}\left(C_{M, y, j}\right):$ effect of drug $j$ on phase $y$ (dependant on PK \\
& calculations for $\left.C_{M, y, j}\right)$
\end{tabular}

\subsection{Cell cycle}

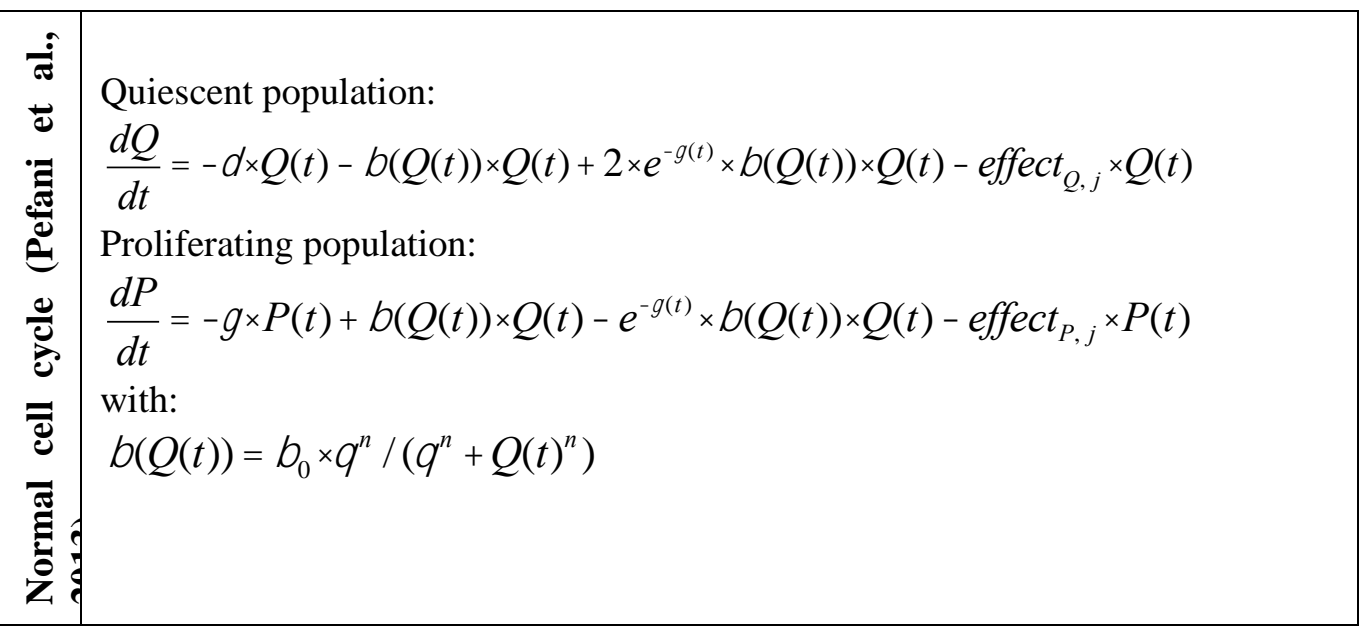




\begin{tabular}{|c|c|}
\hline 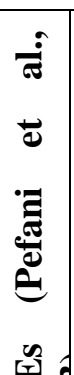 & $\begin{array}{l}\frac{d P_{y}}{d t}=r_{y 1}\left(T_{y 1}\right) \times P_{y 1} \quad r_{y}\left(T_{y}\right) \times P_{y} \quad \text { effect } t_{y, j} \times P_{y} \\
\text { where: } \\
P_{y}(t): \text { population function }(y=\mathrm{G} 0 / \mathrm{G} 1(1), \mathrm{S}(2) \text { or } \mathrm{G} 2 / \mathrm{M}(3) \text { compartment) } \\
T_{y}: \text { duration of cell cycle phase } y \\
r_{y}\left(T_{y}\right): \text { transition function (from } y \text { phase to } y+1 \text { phase, where } y+1=1 \text { if } y=3 \text { ) } \\
\text { effect } t_{y, j}: \text { effect of drug } j \text { on phase } y \text { (dependant on PK calculations) }\end{array}$ \\
\hline 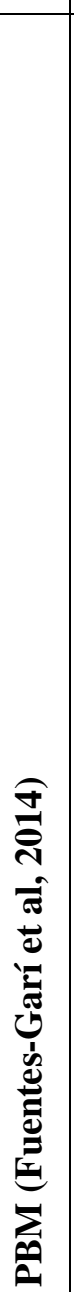 & 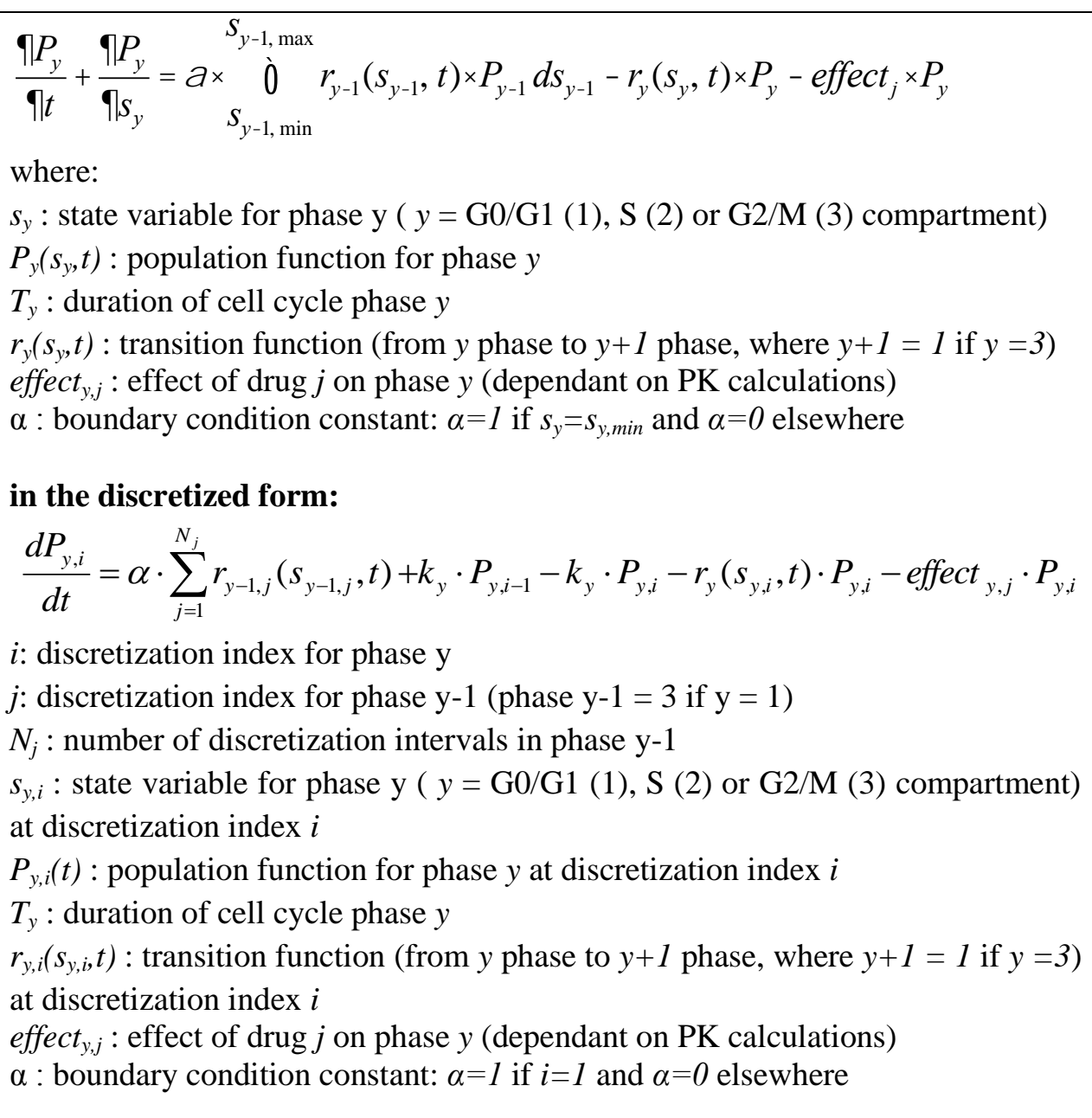 \\
\hline
\end{tabular}

\section{Global sensitivity analysis}

GSA is a powerful technique in the analysis of model robustness with respect to each of its parameters. Briefly, performing GSA involves varying all of the 
estimated/experimentally determined parameters simultaneously using Sobol's method, and observing the model's output. When the output is highly altered in correlation with varied specific parameters, these are said to be significant and an accurate determination of each of them is needed. Conversely, if the output remains unchanged, the parameters are not significant and they can be estimated or left at their nominal values without significant impact on the model's predictions. A concise overview of the GSA method is given below.

The Sobol's sensitivity analysis method is a variance based approach based on the anova decomposition ${ }^{1,2}$. If $f$ is an integrable function defined on the unit hypercube $I^{n}$ and $x \in I^{n}, x=\left(x_{1}, \ldots, x_{n}\right)$ the input variables, the output $f(x)$ of the function may be expressed as:

$$
f(x)=f_{0}+\sum_{s=1}^{n} \sum_{i_{1<\cdots<i_{s}}}^{n} f_{i_{1} \ldots i_{s}}\left(x_{i_{1}}, \ldots, x_{i_{s}}\right)
$$

$f_{0}$ is the mean response of $f$ and the terms $f_{i}\left(x_{i}\right)$ and $f_{i j}\left(x_{i}, x_{j}\right)$ represent the first and second order terms and so on. The formula above is termed ANOVA decomposition. The component functions may then be expressed as integrals of $f$ :

$$
\begin{gathered}
\int f(x) d x=f_{0} \\
\int f(x) \prod_{k \neq i} d x_{k}=f_{0}+f_{i}\left(x_{i}\right) \\
\int f(x) \prod_{k \neq i, j} d x_{k}=f_{0}+f_{i}\left(x_{i}\right)+f_{i j}\left(x_{i}, x_{j}\right)
\end{gathered}
$$

If it is assumed that $f$ is square integrable over $I^{n}$, we have:

$$
\begin{gathered}
\int f^{2}(x) d x-f_{0}=\sum_{s=1}^{n} \sum_{i_{1}<\cdots<i_{s}}^{n} \int f_{i_{1} \ldots i_{s}} d x_{1} \ldots d x_{s} \\
D=\int f^{2}(x) d x-f_{0} \text { and } D_{i_{1} \ldots i_{s}}=\int f_{i_{1} \ldots i_{s}} d x_{1} \ldots d x_{s}
\end{gathered}
$$

The terms represent the variance and partial variance respectively. The Sobol's sensitivity indices (SI) are given by:

\footnotetext{
1 Sobol IM (2001) Global sensitivity indices for nonlinear mathematical models and their Monte Carlo estimates. Mathematics and Computers in Simulation 55(1-3):271-280.

${ }^{2}$ Sobol IM \& Kucherenko SS (2005) On Global sensitivity analysis of quasi-Monte Carlo algorithms. Monte Carlo Methods and Applications 11(1):83-92.
} 
A systematic framework for the design, simulation and optimization of of personalized healthcare:

$$
S_{i_{1} \ldots i_{s}}=\frac{D_{i_{1} \ldots i_{s}}}{D}
$$

where:

$$
\sum_{s=1}^{n} \sum_{i_{1}<\cdots<i_{s}}^{n} S_{i_{1} \ldots i_{s}}=1
$$

If a set of variables $y=\left(x_{1}, \ldots, x_{s}\right)$ is considered and $z$ a set of the complementary variables, we note $x=(y, z)$. Using the previous definition of the variance the total variance of the subset $y$ can be computed as:

$$
D_{y}^{t o t}=D-D_{z}
$$

and:

$$
S_{y}^{t o t}=\frac{D_{y}^{t o t}}{D}
$$

The following inequality holds:

$$
0 \leq S_{y} \leq S_{y}^{t o t} \leq 1
$$

If $S_{y}=S_{y}^{\text {tot }}=0$ then $f$ does not depend on $y$.

If $S_{y}=S_{y}^{\text {tot }}=1$ then $f$ only depends on $y$.

The indices enable us to rank variables and discard unessential variables. Sensitivity analysis indices are usually computed through monte-carlo numerical integration ${ }^{3}$.

$$
D_{y}=\int f(x) f(y, z) d x d z-f_{0}^{2}
$$

\footnotetext{
${ }^{3}$ Sobol IM (2001) Global sensitivity indices for nonlinear mathematical models and their Monte
} Carlo estimates. Mathematics and Computers in Simulation 55(1-3):271-280. 
